PARTICULATE, COLLOIDAL, AND DISSOLVED-PHASE ASSOCIATIONS OF PLUTONIUM, AMERICIUM, AND URANIUM IN WATER SAMPLES FROM WELL 1587 AND SURFACE-WATER SITES SW-51 AND SW-53 AT THE ROCKY FLATS PLANT, COLORADO

By R.A. Harnish, D.M. McKnight, J.F. Ranville, V.C. Stephens, and W.H. Orem

U.S. GEOLOGICAL SURVEY

Water-Resources Investigations Report 96-4067 


\section{U.S. DEPARTMENT OF THE INTERIOR \\ BRUCE BABBITT, Secretary}

U.S. GEOLOGICAL SURVEY

Gordon P. Eaton, Director

The use of trade, product, industry, or firm names is for descriptive purposes only and does not imply endorsement by the U.S. Government.

For additional information write to:

Chief, Branch of Regional Research U.S. Geological Survey

Box 25046, MS 418

Denver, CO 80225
Copies of this report can be purchased from:

U.S. Geological Survey

Branch of Information Services

Box 25286

Denver, CO 80225 


\section{CONTENTS}

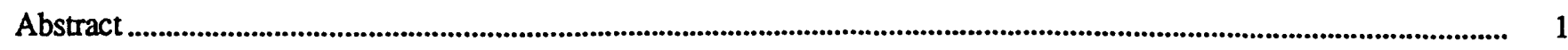

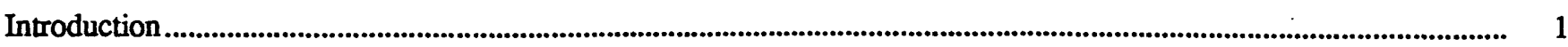

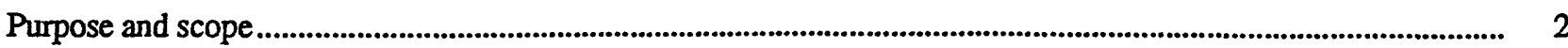

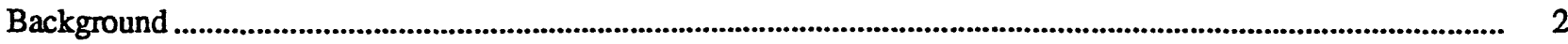

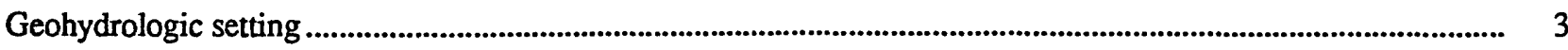

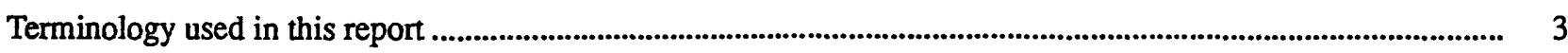

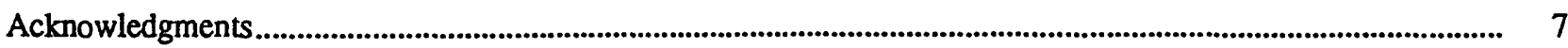

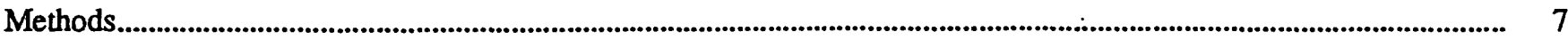

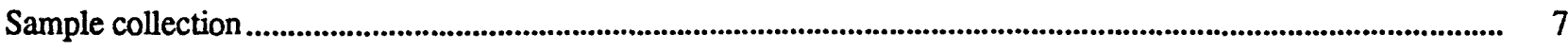

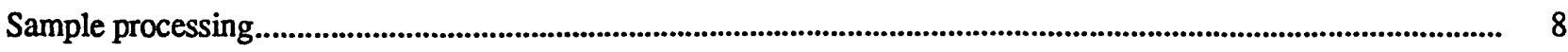

Sample analysis........................................................................................................................................................... ${ }^{-} 18$

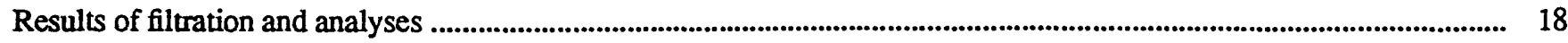

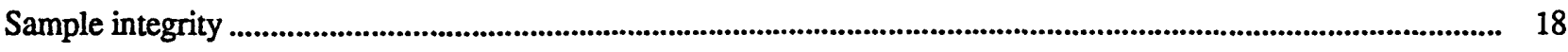

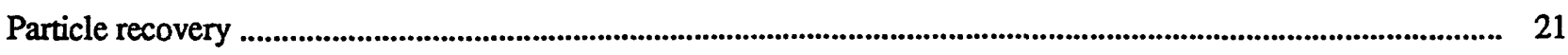

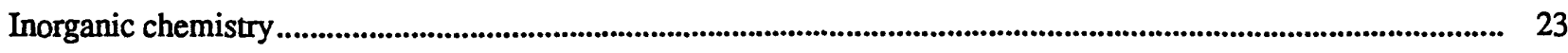

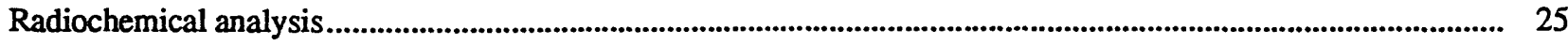

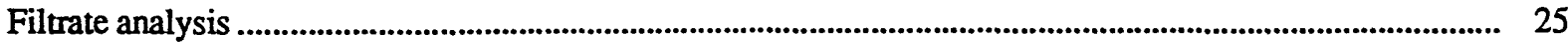

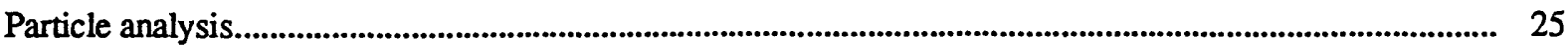

Particle and filter analyses............................................................................................................................ 28

Dissolved-phase associations with fulvic acid.......................................................................................... 33

Dissolved-phase anionic and cationic associations ............................................................................................ 33

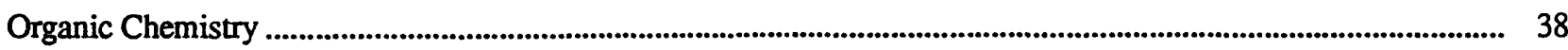

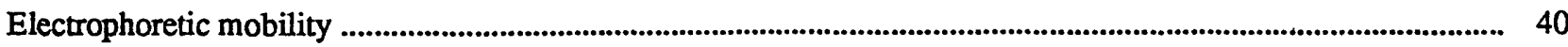

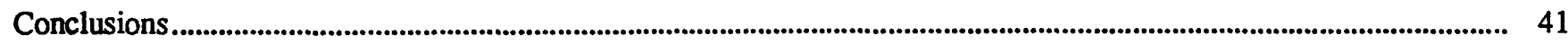

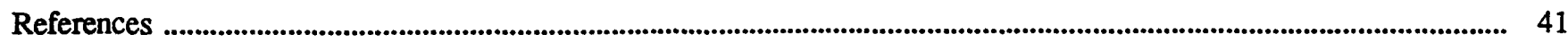

\section{FIGURES}

1. Map showing location of the Rocky Flats Plant...................................................................................................... 4

2. Map showing location of Well 1587, site SW-51, and site SW-53 at the Rocky Flats Plant .............................. 5

3. Diagram showing sampling setup for collection of ground water from Well 1587 at the Rocky Flats Plant.

4. Graphs showing variation in $\mathrm{Eh}, \mathrm{pH}$, specific conductance, temperature, turbidity, dissolved oxygen, and drawdown as a function of volume of water pumped from Well 1587

5. Diagram showing filtration and resin extraction scheme used in processing waters collected from Well 1587, site SW-51, and site SW-53

6. Graph showing ${ }^{13}$ carbon-nuclear magnetic resonance spectrum of fulvic acid isolated from the dissolved phase of water from A, Well 1587; B, site SW-51; and C, site SW-53 


\section{TABLES}

1. Physical and chemical measurements of 0.45 -micrometer filtered water from Well 1587 , and surface-water at sites SW-51 and SW-53.

2. Classification and nominal physical characteristics of suspended material used in this report................................ 7

3. Protocols used for filtration of water from Well 1587 and surface-water sites SW-51 and SW-53......................... 13

4. Protocols used for the resin extraction of the 10,000-Dalton filtrate of water from Well 1587 and surface-water sites SW-51 and SW-53

5. Radiochemical analysis of field blanks for plutonium 239 and 240 .

6. Radiochemical analysis of field blanks for americium 241

7. Radiochemical analysis of field blanks for uranium 233 and 234

8. Detection limits for inductively coupled plasma/atomic-emission spectrometry analysis.

9. Detection limits for anion analyses.

10. Specific-conductance and $\mathrm{pH}$ measurements made during the course of ultrafiltration of water from Well 1587

11. Measurements of $\mathrm{pH}$ made during the course of ultrafiltration of water from surface-water sites SW-51 and SW-53.

12. Particle recovery from filtration of water from Well 1587 and surface-water sites SW-51 and SW-53.

13. Concentrations of inorganic species in water from Well 1587 and surface-water sites $S W-51$ and SW-53

14. Results of radiochemical analysis of water from Well 1587 and surface-water sites SW-51 and SW-53

15. Results of radiochemical analysis of dried retentates and algal samples recovered in the filtration of water from Well 1587 and surface-water sites SW-51 and SW-53

16. Results of radiochemical analysis of recovered retentates, particles adhering to filters, and dissolved phase in water from Well 1587

17. Results of radiochemical analysis of recovered retentates, particles adhering to filters, and dissolved phase in water from surface-water site SW-51

18. Results of radiochemical analysis of recovered retentates, particles adhering to filters, and dissolved phase in water from surface-water site SW-53

19. Results of radiochemical analysis of less than 10,000-Dalton dissolved phase in water from Well 1587 for fulvic-acid, anionic, and cationic associations

20. Results of radiochemical analysis of less than 10,000-Dalton dissolved phase in water from surface-water site SW-51 for fulvic-acid, anionic, and cationic associations

21. Results of radiochemical analysis of less than 10,000-Dalton dissolved phase in water from surface-water site SW-53 for fulvic-acid, anionic, and cationic associations

22. Summary of fulvic acid, anionic, and cationic association ratios of actinides in the less than 10,000-Dalton dissolved phase in Well 1587 and surface-water sites SW-51 and SW-53

23. Ratios of anionic activity concentrations to the sum of the fulvic-acid-bound activity concentration and the anionic activity concentration after XAD-8 treatment of sample

24. Concentration of dissolved organic carbon and fulvic acid in water from Well 1587 and surface-water sites SW-51 and SW-53

25. Electrophoretic mobility of particles recovered by filtration of water from Well 1587 and surface-water sites SW-51 and SW-53 


\title{
Particulate, Colloidal, and Dissolved-Phase Associations of Plutonium, Americium, and Uranium in Water Samples from Well 1587 and Surface-Water Sites SW-51 and SW-53 at the Rocky Flats Plant, Colorado
}

\author{
By R.A. Harnish, D.M. McKnight, J.F. Ranville, V.C. Stephens, and W.H. Orem
}

\begin{abstract}
The potential for off-site transport of plutonium in ground or surface water has been a concern in the remediation efforts at the Rocky Flats nuclear facility near Denver, Colorado. The transport and fate of dissolved radionuclide species are inherently different from those for particulate or colloidal phases involving radionuclides. To distinguish among dissolved, colloidal, and particulate phases, water samples were collected and were filtered in series using spiral-flow filtration and tangential-flow ultrafiltration. One of the surface-water samples had a high content of larger particles; in this sample, plutonium and americium were distributed mainly in the particulate phase. Uranium was distributed mainly in the dissolved phase. For the other surface-water sample and the ground-water sample, the colloidal fraction also was important in plutonium and americium distribution. The filtrates from the 10,000-Dalton ultrafilter were fractionated, using ion-exchange resins and XAD-8 resin for isolation of fulvic acids. Most of the dissolved plutonium was associated with the fulvic acid for all three samples. A portion of the americium and uranium activity ( 5 percent to 21 percent) was associated with fulvic acid, but most americium and uranium were present in an anionic form not associated with fulvic acid, indicating the possible importance of other organic ligands or inorganic anionic species.
\end{abstract}

\section{INTRODUCTION}

The U.S. Department of Energy administers the operation of the Rocky Flats Plant, a government-owned, contractor-operated facility for nuclear-material processing located in northern Jefferson County, Colorado, about $26 \mathrm{~km}$ northwest of downtown Denver. The plant opened in 1952, and plutonium (Pu) processing continued until 1990 , when the principal mission of the plant changed from manufacture and processing of plutonium components to pollutant identification and remediation. Pursuant to the U.S. Department of Energy's environmental restoration program for the Rocky Flats Plant, and in cooperation with the U.S. Department of Energy, in 1991, the U.S. Geological Survey (USGS) began a study of the potential for facilitated transport of Pu, americium (Am), and uranium $(U)$ by colloidal-size particles at two surface-water sites and one ground-water site at the plant. This study was designed to determine the predominant phases that control the transport of $\mathrm{Pu}, \mathrm{Am}$, and $\mathrm{U}$ in surface and ground water at the Rocky Flats Plant and, in particular, the potential for transport of these elements as colloids or as complexes with humic substances. The results of an initial sampling of the water from Well 1587 in November 1991 are described in a previous report by Harnish and others (1994). In summary, the conclusions in that study about actinide distribution were that:

1. About 65 percent of $\mathrm{Pu} 239$ and 240 was associated with particulate and colloidal phases.

2. The particulate fraction (greater than $5 \mu \mathrm{m}$ ) was rich in iron oxyhydroxides; in smaller colloids, clay minerals and organic material were important.

3. Copper and zinc were present in the smallest colloid fraction. 
4. Colloid concentrations were low (less than $1 \mathrm{mg} / \mathrm{L}$ ) in water from Well 1587.

5. Colloid-facilitated transport of radionuclides may be episodic, associated with rain or snowmelt.

\section{Purpose and Scope}

This report describes the results from the May 1992 sampling of the water from Well 1587 and the surfacewater sites SW-51 and SW-53. Specifically, the distribution of Pu, Am, and U in the water among particulate, colloidal, and dissolved phases was determined.

\section{Background}

Particulate and colloidal particles are important in natural water for transport, bioavailability, and reactivity of organic and trace-metal contaminants. Colloidal particles, those particles generally greater than $1 \mathrm{~nm}$ and less than $5 \mu \mathrm{m}$ in diameter, are especially important components because of their high specific surface areas (which facilitate reactions between solids and solution) and because of their small size (which inhibits settling). Because the term "colloidal" indicates only a size classification, the chemical composition and reactivity of colloids in natural water are varied. Organic colloidal forms include cellular exudates and partly to extensively degraded detrital material that can be associated with mineral phases (Ranville and others, 1991). Inorganic forms include clays and insoluble metal oxides. Colloidal particles have been detected in ground water (Salbu and others, 1985; Degueldre and others, 1989) and may be mobile in aquifers (Harvey and others, 1989). In a study of colloids in a reservoir, Ranville and others (1991) reported that iron (Fe), manganese (Mn), and zinc ( $\mathrm{Zn}$ ) were concentrated in the organic colloid fraction. Association of contaminants having low aqueous solubilities with ground-water colloids can greatly affect contaminant transport (McCarthy and Zachara, 1989; Penrose and others, 1990).

A substantial body of research about the fate and transport of actinides (those radioactive elements with atomic numbers 89 to 103) in natural water has been reviewed (Coughtrey and others, 1984) and has indicated the complexity of actinide interactions with geologic media in aquatic systems. The environmental chemistry of the actinides, and especially $\mathrm{Pu}$, is complex because of the actinide tendency to be in multiple oxidation states in solution, to hydrolyze, and to polymerize (Dahlman and others, 1976). The behavior of these actinides in natural systems is dependent on an array of environmental effects, few of which have been unambiguously quantified. Speciation in solution and the tendency to sorb onto particles or geologic media are profoundly affected by variables, including $\mathrm{pH}$, redox state, particle surface chemistry, and the presence of complexing organic or inorganic ligands. In a broad environmental sense, sorption/desorption reactions can be mediated by ion exchange, precipitation and mineral formation, complexation and hydrolysis, oxidation and reduction reactions, and colloid and polymer formation (Onishi and others, 1981). Because of the complexity of actinide environmental chemistry, few generalizations can be made about the environmental fate of the actinides.

The complexation of trace metals by dissolved humic substances is potentially important in the transport of trace metals in natural water. The predominant class of humic substances in natural water is the acid soluble fraction, fulvic acid. Aquatic fulvic acids have molecular weights ranging from 400 to 2,000 Daltons and have a content of carboxylic-acid functional groups of 4 to $6 \mathrm{meq} / \mathrm{g}$ (Aiken, 1985). These carboxylic-acid groups can form complexes with positively charged metals; for example, $\mathrm{Cu}$ and Fe form charge transfer complexes that have relatively high formation constants (McKnight and Wershaw, 1989). The concentrations of fulvic acids in natural water ranged from $0.5 \mathrm{mg} \mathrm{C} / \mathrm{L}$ in ground water to $30 \mathrm{mg} \mathrm{C} / \mathrm{L}$ for blackwater, and the corresponding concentrations of carboxylic groups (about 2-200 $\mu \mathrm{M}$ ) are often several orders of magnitude greater than the concentrations of trace metals (Thurman, 1985). Such high ligand-to-metal ratios enhance the function of fulvic-acid complexation in controlling the transport and fate of trace-metal contaminants. Aquatic fulvic acids are characteristically persistent in natural water, although sorption, aggregation, and microbial and photolytic degradation are important controlling (McKnight and others, 1990; McKnight and others, 1992). Thus, the transport and fate of trace metals complexed by fulvic acid follow different pathways than trace metals associated with particulate or colloidal phases. 
The potential exists for formation of complexes involving actinides and carboxylic-acid groups in naturally occurring fulvic acid. Plutonium, for example, forms complexes with organic carboxylates, and complexing agents, such as NTA and EDTA, which are used in some decontamination activities. Because of the heterogeneity in fulvic acids and the importance of ligand-to-metal ratios in controlling complexation, studies of these interactions in an actual environmental setting are potentially more definitive than laboratory studies.

\section{Geohydrologic Settling}

The Rocky Flats Plant is located east of the Front Range of the Rocky Mountains on a broad, east-sloping plain of alluvial fans between the stream-cut valleys of North Walnut Creek and Woman Creek (figs. I and 2). Details of the geologic and hydrologic characteristics of the area within the plant boundaries have been described in previous reports (Rockwell International, 1987; EG\&G, 1991; Harnish and others, 1994). Well 1587 is a shallow alluvial monitoring well in the Woman Creek Basin, about $90 \mathrm{~m}$ east of the $903 \mathrm{Pad}$ (fig. 2). The well is cased with PVC pipe $10 \mathrm{~cm}$ in diameter, extends about 6.9 meters through the alluvium to bedrock, and is screened through the lower $4.9 \mathrm{~m}$ of alluvium. The seep at site SW-51 originates about $180 \mathrm{~m}$ east-southeast of the $903 \mathrm{Pad}$ (fig. 2), then becomes a shallow stream that empties into a drainage ditch. The surface-water seep at site SW-51 is formed where ground water enters permeable formations on a slope and is ephemeral in response to rainfall and infiltration in the vicinity. The seep at site SW-53 is a marshy area fed by surface water in a depression about $275 \mathrm{~m}$ east-southeast of the $903 \mathrm{Pad}$ area. All three sampling locations are downgradient from the $903 \mathrm{Pad}$ area, a potential source of actinide contamination. Physical and chemical measurements (table 1) indicate that these are well buffered, slightly alkaline, calcium/magnesium bicarbonate type waters.

\section{Terminology Used in this Report}

Filtration in environmental sampling traditionally has used $0.45-\mu \mathrm{m}$ filters for separating the particulate phase from the dissolved phase. This choice of filter size is arbitrary because size distributions for environmental particles in water form a continuum from less than $1 \mathrm{~nm}$ to hundreds of micrometers (Buffle and others, 1989,1992) (table 2). For the present study, five filter pore sizes were used for particle isolation and fractionation, and the following terminology is used to distinguish among the fractions:

1. The term "particle" refers to all phases of a sample that are not dissolved and includes colloids and particulates.

2. The term "particulate" refers to the phase that is retained by a 5.0- $\mu \mathrm{m}$ filter (used for samples from Well 1587 and SW-51) or a 3.0- $\mu \mathrm{m}$ filter (used for the sample from 787SW-53).

3. The term "colloid" includes three distinct particle fractions:

a. Particles that pass through a $5.0-\mu \mathrm{m}$ (or $3.0-\mu \mathrm{m}$ ) filter, but are retained on a $0.45-\mu \mathrm{m}$ filter.

b. Particles that pass through a $0.45-\mu \mathrm{m}$ filter, but are retained on a 100,000 -Dalton filter.

c. Particles that pass through a 100,000-Dalton filter, but are retained on a 10,000-Dalton filter.

A 100,000 -Dalton filter corresponds approximately to a 5- to 8-nm $(0.005$ - to $0.008-\mu \mathrm{m})$ filter. A 10,000 Dalton filter corresponds approximately to a $1-\mathrm{nm}(0.001-\mu \mathrm{m})$ filter.

4. The term "dissolved" denotes the phase that passes through a 10,000-Dalton filter. 


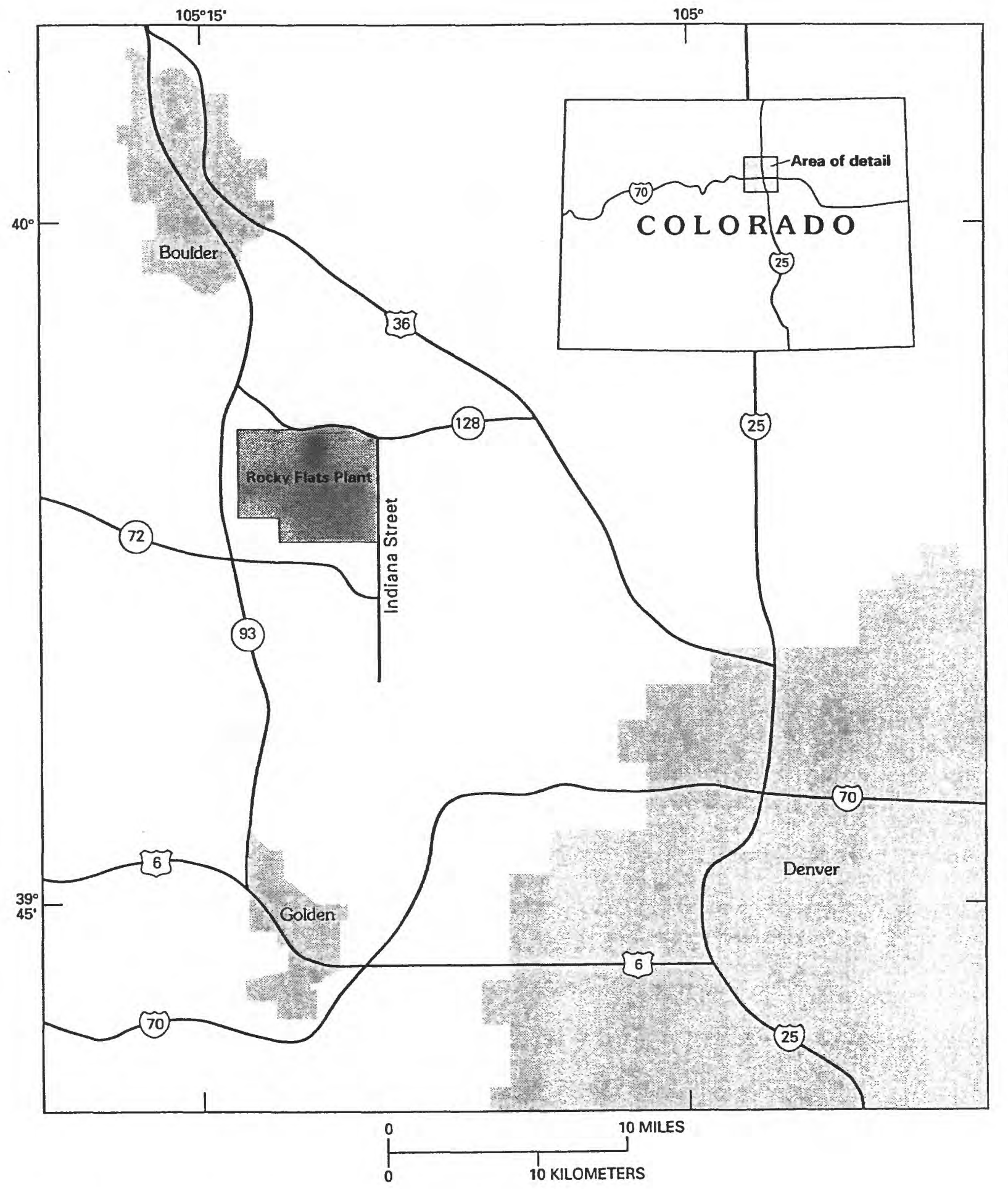

Figure 1. Location of the Rocky Flats Plant. 

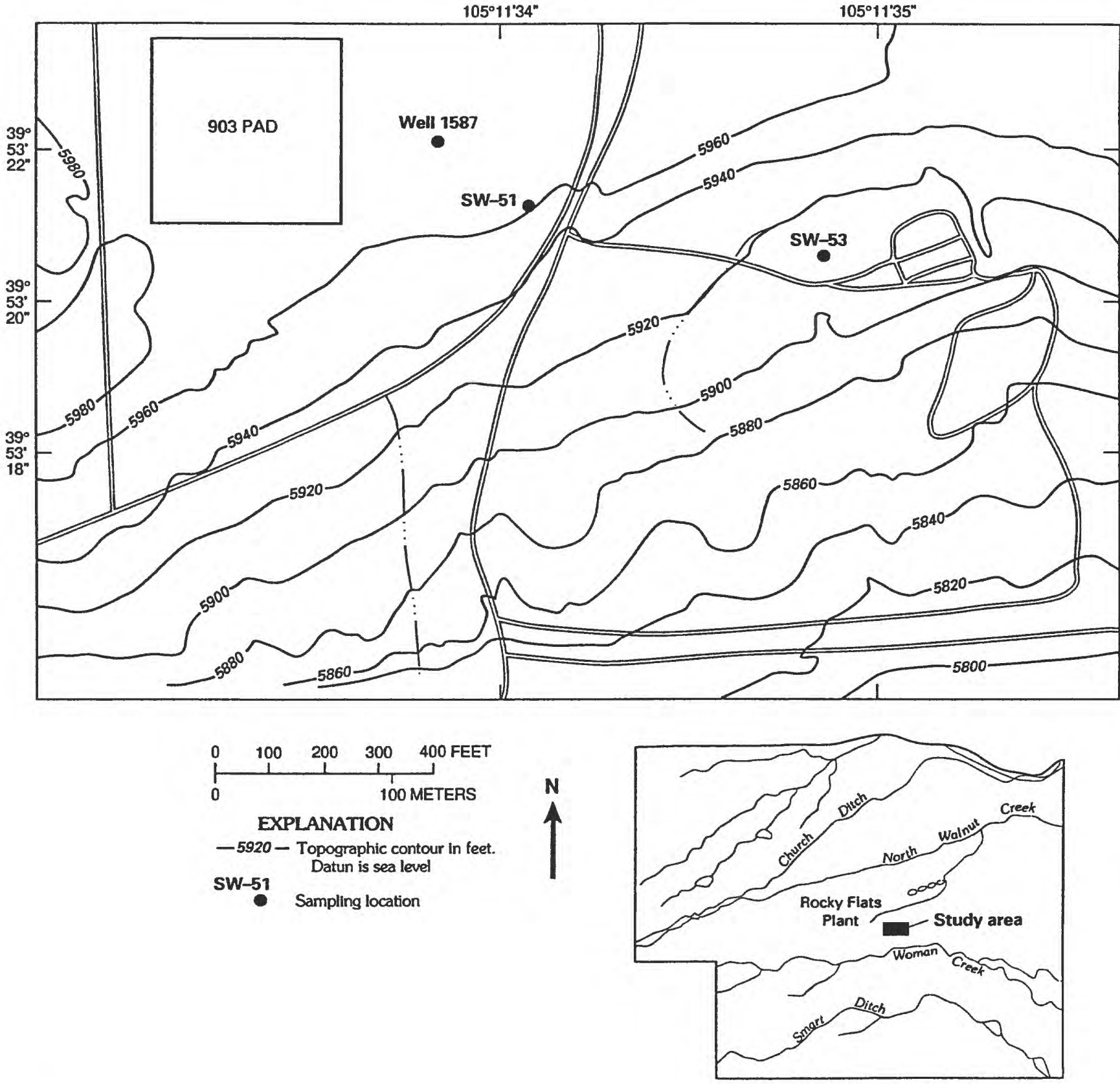

Figure 2. Locations of Well 1587, site SW-51, and site SW-53 at the Rocky Flats Plant. 
Table 1. Physical and chemical measurements of 0.45 -micrometer filtered water from Well 1587 and surface-water sites SW-51 and SW-53.

[All values in milligrams per liter unless otherwise noted; $<$, less than; - , no data]

\begin{tabular}{|c|c|c|c|}
\hline Properties and constituents & Well 1587 & SW-51 & sW-53 \\
\hline $\mathrm{pH}^{1}$ & 7.66 & 7.76 & 7.57 \\
\hline Temperature (degrees Celsius) ${ }^{1}$ & 14.6 & 15.7 & 16.1 \\
\hline Alkalinity ${ }^{1}$ & 207 & 250 & 366 \\
\hline Eh (millivolts) ${ }^{1}$ & 215 & - & - \\
\hline Dissolved oxygen ${ }^{1}$ & 4.8 & 8.6 & 8.9 \\
\hline Bicarbonate $\left(\mathrm{HCO}_{3}\right)$ & 180 & 280 & 343 \\
\hline Carbonate $\left(\mathrm{CO}_{3}\right)$ & $<5.0$ & $<5.0$ & $<.0$ \\
\hline Fluoride (F) & $<0.5$ & $<0.5$ & 0.8 \\
\hline Chloride (Cl) & 7.0 & 22.0 & 72.0 \\
\hline Sulfate $\left(\mathrm{SO}_{4}\right)$ & 11.0 & 18.0 & 25.0 \\
\hline Nitrite plus nitrate $\left(\mathrm{NO}_{2}\right.$ and $\left.\mathrm{NO}_{3}\right)$ & 2.5 & 4.9 & 0.2 \\
\hline Carbon dioxide $\left(\mathrm{CO}_{2}\right)^{1}$ & 9.3 & - & - \\
\hline Aluminum (Al) & 0.069 & $<0.020$ & 0.050 \\
\hline Barium (Ba) & 0.116 & 0.160 & 0.201 \\
\hline Calcium (Ca) & 96.90 & 103.4 & 132.0 \\
\hline Iron $(\mathrm{Fe})$ & $<0.020$ & $<0.020$ & $<0.020$ \\
\hline Potassium (K) & $<1.0$ & $<1.0$ & 2.65 \\
\hline Magnesium (Mg) & 7.77 & 8.52 & 25.80 \\
\hline Manganese (Mn) & $<0.010$ & $<0.010$ & 0.107 \\
\hline Sodium (Na) & 5.83 & 7.25 & 17.80 \\
\hline Silicon (Si) & 5.99 & 5.30 & 6.92 \\
\hline Strontium (Sr) & 0.337 & 0.354 & 0.746 \\
\hline
\end{tabular}

${ }^{1}$ Field measurements on unfiltered samples. 
Table 2. Classification and nominal physical characteristics of suspended material; adapted from Buffle and others, 1992

\begin{tabular}{lccc}
$\begin{array}{l}\text { [um, micrometer, }>\text {, greater than; } \mathrm{cm} / \mathrm{s} \text {, centimeter per second; } \mathrm{km} / \mathrm{yr} \text {, kilometer per year, }<\text {, less than; } \\
\text { Phase }\end{array}$ & $\begin{array}{c}\text { Diameter } \\
(\mu \mathrm{m})\end{array}$ & $\begin{array}{c}\text { Molecular weight } \\
(\text { Dalton })\end{array}$ & Sedlmentation rate \\
\hline Particulate & $62-2,000$ & $>10^{8}$ & $0.4-20 \mathrm{~cm} / \mathrm{s}$ \\
Particulate & $5-62$ & $>10^{8}$ & $0.5-124 \mathrm{~km} / \mathrm{yr}$ \\
Colloid & $2-5$ & $>10^{8}$ & $0.1-0.5 \mathrm{~km} / \mathrm{yr}$ \\
Colloid & 1 & $10^{8}$ & $<0.1 \mathrm{~km} / \mathrm{ys}$ \\
Colloid & 0.45 & $10^{7}$ & $<0.1 \mathrm{~km} / \mathrm{yr}$ \\
Colloid & 0.1 & $10^{6}$ & $<0.1 \mathrm{~km} / \mathrm{ys}$ \\
Colloid & 0.001 & $10^{4}$ & $<0.1 \mathrm{~km} / \mathrm{yr}$ \\
Dissolved & $<0.001$ & $<10^{4}$ & - \\
\hline
\end{tabular}

5. In addition, the following terms refer to filtration fractions: "filtrate" is the water and compounds of any size that pass through a filtration membrane, and "retentate" is a material of any size that is retained by a filtration membrane.

6. The term "fulvic acid" is operationally defined as dissolved organic acid isolated on XAD-8 resin under conditions described by Thurman and Malcolm, (1981).

\section{Acknowledgments}

The authors wish to thank Scott Grace (U.S. Department of Energy), Gregory Wetherbee (EG\&G Rocky Flats, Inc.), and Michael Harris (EG\&G Rocky Flats, Inc.) for valuable scientific discussions and logistical assistance. We also thank Jennifer Aiken for statistical verification of radioisotope activity calculations.

\section{METHODS}

\section{Sample Collection}

The task of isolating colloids from natural water is complicated by the unstable nature of these particles and their low concentrations. Ideally, the isolated particles are unaltered from their natural state in terms of size, morphology, charge characteristics, surface area, chemical composition, and sorbed species. A practical goal is a minimal perturbation during the sampling and processing of the particles. This need for minimal perturbation necessitates sample acquisition and filtration protocols that minimize physical disruption of the particles and that avoid physiochemical processes, such as coagulation, that alter colloid characteristics (Ryan, 1988). Exposure to the atmosphere, exposure to light, and departures from in-situ water temperature can profoundly alter the physiochemical characteristics of the water sample. These considerations are especially critical when sampling ground 
water. Exposure of the water sample to the atmosphere promotes degassing of carbon dioxide $\left(\mathrm{CO}_{2}\right)$ and a concurrent increase in $\mathrm{pH}$. The redox chemistry of the sample is altered by the introduction of oxygen, promoting oxidative precipitation of dissolved metal species and resulting changes in particle-size distribution. Exposure to light increases photoreductive dissolution of iron oxide colloids (Ryan, 1988). Increases in temperature affect the kinetics of reactions occurring in the sample, increasing reaction rates and biological activity.

Well 1587 and seeps at sites SW-51 and SW-53 were sampled during May 11 through 28, 1992. Samples were obtained using a peristaltic pump; water samples were stored in $209 \mathrm{~L}$ polyethylene barrels for transport to a mobile onsite laboratory for processing. A total sample volume of $833 \mathrm{~L}$ was collected at Well 1587, 300 L at seep SW-51, and $120 \mathrm{~L}$ at seep SW-53. Processing of the samples began within several hours of collection.

Because of the potential for contamination by airbome particles at these sites, sample collection and processing were done in a clean system. Well 1587 water (ifg. 3) was isolated with an inflatable packer at the well, and subsequent air/sample contact was minimized with a combination of: (1) a 0.3 percent $\mathrm{CO}_{2}$, balance nitrogen atmosphere (to approximate dissolved $\mathrm{CO}_{2}$ in the ground water) maintained in contact with the sample during sampling and storage; (2) positive pressure maintained throughout the collected sample; and (3) high-efficiency particle-filter (HEPA) filtration of ambient air that might come in contact with the sample. At all stages of filtration and processing, the samples were shielded from light. Opaque tubing and storage vessels were used during sampling, and all subsequent processing was done under subdued light. To minimize shear-induced detachment of sorbed particles and resuspension of settled particles in the aquifer matrix, the pumping rate was maintained at less than $281 \mathrm{~mL} / \mathrm{min}$ for the duration of sampling of the well. This rate of pumping produced virtually no drawdown in the ground-water level after about $5 \mathrm{~L}$ of water was withdrawn from the well. Variations in $\mathrm{Eh}, \mathrm{pH}$, specific conductance, temperature, turbidity, dissolved oxygen, and drawdown were monitored during initial purging of the well as a check on sufficiency of purging and intermittently during sample collection as a check on constancy of sample composition. Fifteen well-casing volumes (12 L) were pumped and discarded during initial purging before the measured parameters stabilized, and sample collection was begun. Measured parameters remained relatively stable during the course of sample acquisition (igg. 4 ), except for temperature, which indicated changes in daytime ambient air temperatures. Collected waters were stored in pre-cleaned polyethylene barrels and iced to maintain approximately in-situ ground-water temperatures.

For the oxic surface waters from seeps SW-51 and SW-53, parameter monitoring during collection was lesS extensive, although the same sampling protocols (pumping rate, HEPA filtration of air in contact with sample, and temperature control) were followed. Additionally, a polyethylene-tray sampling device was used at the surfacewater sites to isolate the bed sediments and prevent disturbance of the sediments during sampling. At both surfacewater sites, grab samples of algae were obtained for radiochemical analysis.

\section{Sample Processing}

The samples from Well 1587 and seep SW-51 were processed using a combination of spiral-flow prefiltration and crossflow ultrafiltration. The principles governing these filtration modes are discussed by Harnish and others (1994). For the sample from seep SW-53, glass-fiber-filter depth filtration was substituted for spiral-flow filtration because the high suspended-particle concentrations made spiral-flow filtration impractical because of low filtration rate. Because depth filtration may retain particles smaller than the filter cutoff size because of pore clogging and because the nominal filter size is smaller $(3.0 \mu \mathrm{m})$ than that used at the other sampling sites $(5.0 \mu \mathrm{m})$, results of chemical and radiochemical analyses for water from seep SW-53 may be biased toward greater activity in the particulate fraction, although the extent of this bias is unknown. No measurable diminution of filtration rate was indicated during the 3.0- $\mu \mathrm{m}$ filtration of water from SW-53, however, indicating that minimal filter clogging occurred. All filters were precleaned by sequential washing with $0.1 \mathrm{~N} \mathrm{NaOH}$ and $0.1 \mathrm{~N} \mathrm{HCl}$ and a final rinse with distilled water. This procedure has been shown to be effective in removing organic and inorganic contamination from the filters (Ranville and others, 1991). Filtration equipment was acid washed before use in 5-percent $\mathrm{HNO}_{3}$ and then rinsed with distilled water. 


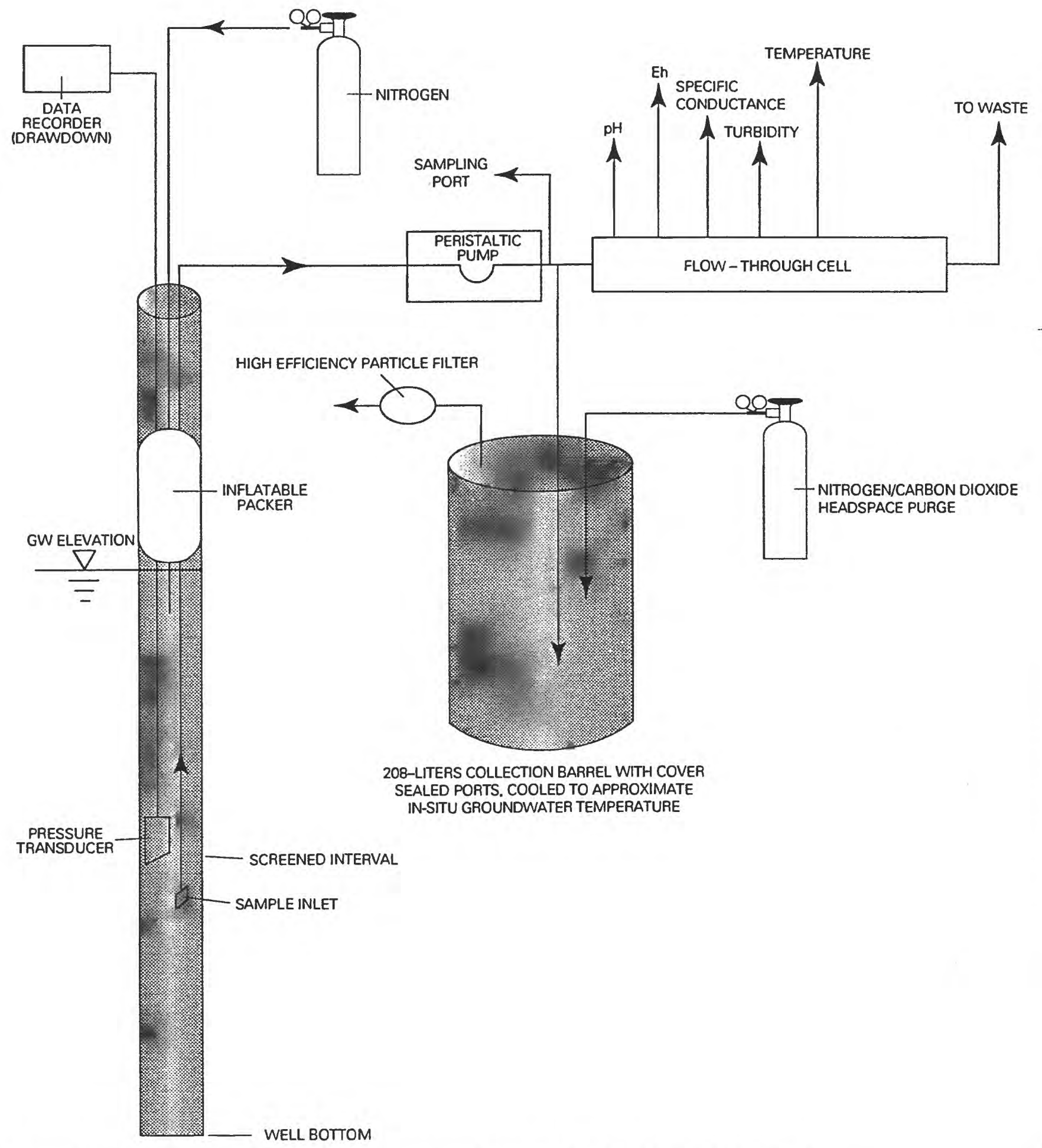

Figure 3. Sampling setup for collection of ground water from Well 1587 at the Rocky Flats Plant. 

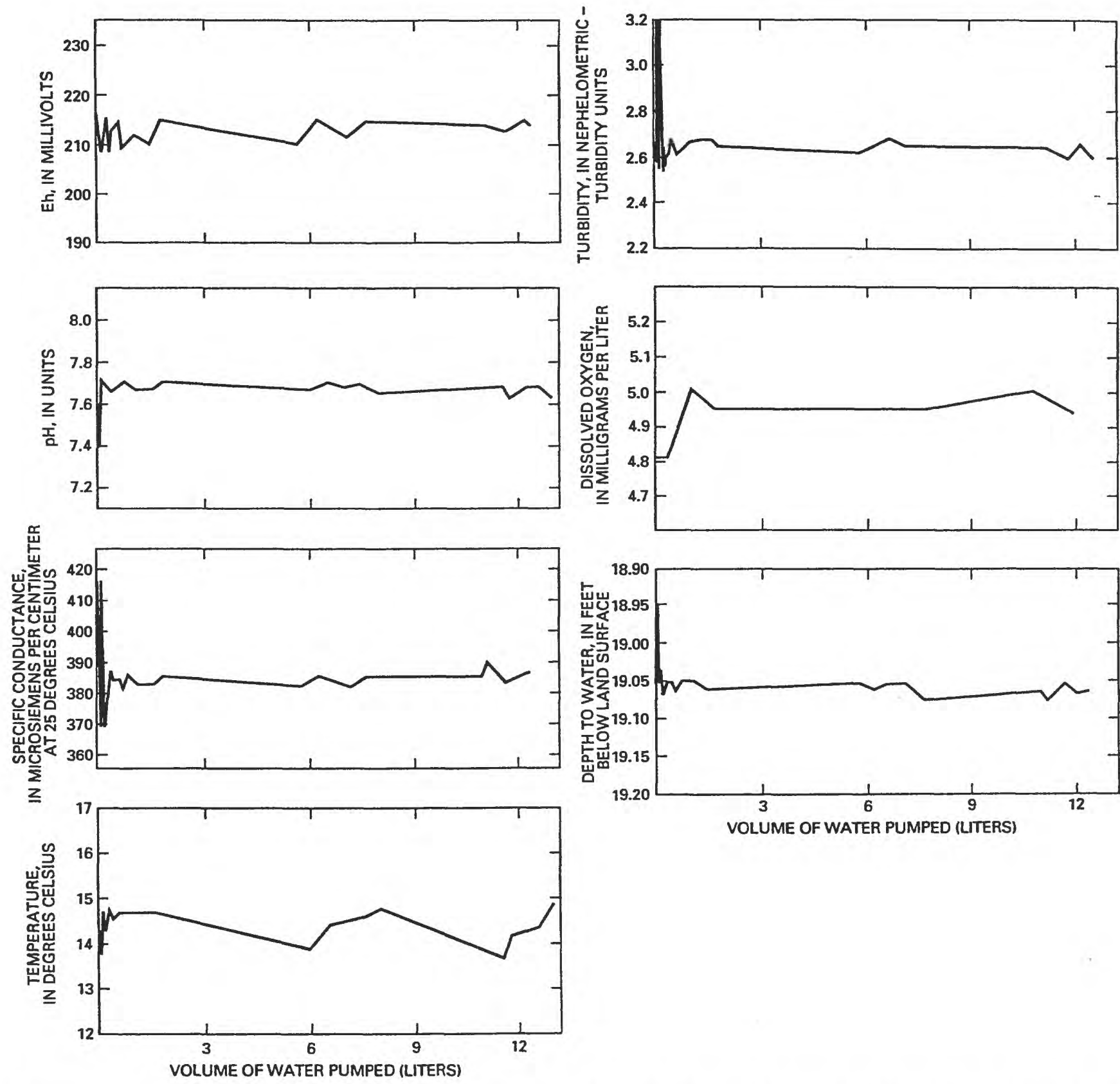

Figure 4. Variation in $\mathrm{Eh}, \mathrm{pH}$, specific conductance, temperature, turbidity, dissolved oxygen, and draw-down as a function of volume of water pumped from Well 1587. 
The filtration rate ranged from 400 to $500 \mathrm{~mL} / \mathrm{min}$ for the 5.0 - and $3.0-\mu \mathrm{m}$ filtration to 100 to $300 \mathrm{~mL} / \mathrm{min}$ for the $0.45-\mu \mathrm{m}, 100,000$ - and 10,000-Dalton filtrations. The filtration sequence is shown in figare 5 . The unfiltered sample was first filtered by spiral-flow filtration through a 5.0- $\mu \mathrm{m}$ polycarbonate filter for Well 1587 and seep SW51 and 3.0- $\mu \mathrm{m}$ glass-fiber filter for seep SW-53. Particles greater than $5 \mu \mathrm{m}$ were recovered from the $5.0-\mu \mathrm{m}$ filters by placing the filters in a petri dish and gently rinsing the filter surface. Retentates thus obtained were refrigerated at $4^{\circ} \mathrm{C}$. The 3.0- $\mu \mathrm{m}$-depth filtration of the sample from SW-53 precluded recovery of the greater than 3.0- $\mu \mathrm{m}$ particles by rinsing, and analysis of the retentate for radionuclides at this site was accomplished by acid leaching of the filter.

The filtrate from the $5.0-\mu \mathrm{m}$ (or $3.0-\mu \mathrm{m}$ ) filtration then was filtered through several $0.45-\mu \mathrm{m}$ polyvinylidene fluoride filters by tangential filtration, producing a $0.45-\mu \mathrm{m}$ filtrate, a $0.45-\mu \mathrm{m}$ concentrated retentate, and particles adhering to the filters. Following filtration, the filtration systems were disassembled, and adhering colloids were removed from the filters by placing a filter in a Teflon bag along with some retentate and gently rubbing off the colloids; this process was repeated for all filters of each size range. The collected colloids were combined with the retentate from the fraction and were refrigerated at $4^{\circ} \mathrm{C}$. At each step of the filtration, samples were taken of filtrates and retentates for radiochemical and chemical analysis. Two subsequent tangential-filtration steps $(100,000$ and 10,000 Dalton) were done in the same manner for the isolation of colloids. Filtration protocols are listed in table 3.

The final 10,000-Dalton filtrate was processed through a series of XAD-8, anion-exchange, and cationexchange resins. The resin XAD-8 is a nonionic macroporous sorbent that has been used to isolate fulvic acids from aquatic systems (Thurman and Malcolm, 1981). Methods for the isolation of aquatic fulvic acids have been reviewed by Aiken (1985). Protocols for resin extraction used in this study are listed in table 4. Parts of the 10,000Dalton filtrate, acidified to $\mathrm{pH} 1.8$, were passed through a column of XAD-8. The fulvic acids retained on the resin were eluted in $0.1 \mathrm{~N} \mathrm{NaOH}$ and then acidified. The acidified eluates were combined and reconcentrated on the $\mathrm{XAD}-8$ column. The final eluate was hydrogen saturated on a cation-exchange resin, and the fulvic acid was lyophilized for analysis.

The eluate from the XAD-8 extraction was adjusted to its original $\mathrm{pH}$ ( 7.66 for Well 1587 water and 7.76 and 7.57 for SW-51 and SW-53 surface water) using $\mathrm{NaOH}$, in preparation for subsequent extraction by anion- and cation-exchange resins. One-hundred liters of post-XAD eluant from each site was extracted sequentially in a batch mode using 80 grams of Biorad AG1-X8 anion-exchange resin (100-200 mesh, chloride form) and then with 80 grams of Biorad AG50W-X8 cation-exchange resin (100-200 mesh, hydrogen form). The resins were subsequently ashed and submitted for radionuclide analysis.

Another $100-\mathrm{L}$ part of the 10,000 -Dalton filtrate from each site, which had not been previously extracted with $\mathrm{XAD}-8$, was extracted sequentially by the same anion- and cation-resin treatment protocol. Because fulvic acids contain carboxylic-acid groups that are negatively charged at the neutral $\mathrm{pH}$ of the water samples, the fulvic acids also are removed from solution by an anion-exchange resin. The resins were then ashed and submitted for analysis of radionuclide activity.

Laboratory-grade deionized water was filtered by the same filtration protocol as the field water samples and then analyzed at each filtration step for Pu 239 and 240, Am 241, and $U 233$ and 234 activity. The filters were digested and analyzed for the same radionuclides. The 10,000-Dalton filtrate then was passed through XAD-8, cation-, and anion-exchange resins; eluates and the resins were similarly analyzed for radionuclide activity. In no case did detected activities of Pu 239 and 240, Am 241, or U 233 and 234 substantially exceed detection limits (tables 5-7), confirming that the filtration equipment and protocol did not substantially affect the reported activities of these actinides. 


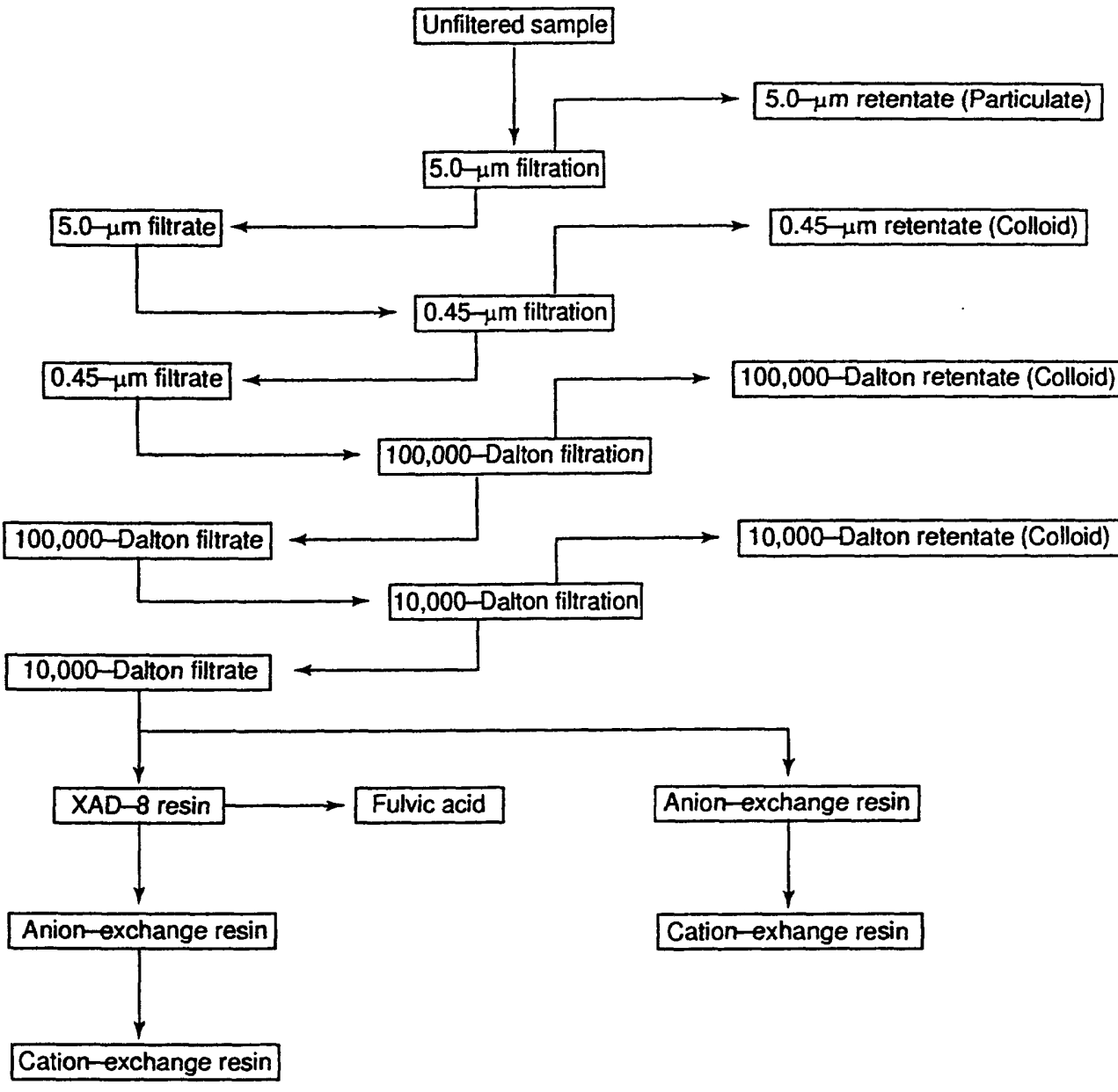

Figure 5. Filtration and resin extraction scheme used in processing waters collected from Well 1587, site SW-51, and site SW-53. 
Table 3. Protocols used for filtration of water from Well 1587 and surface-water sites SW-51 and SW-53 [ $\mu \mathrm{m}$, micrometers, $\mathrm{cm}^{3}$, cubic centimeters; $L$, liters;,- , no data]

\begin{tabular}{|c|c|c|c|c|c|c|}
\hline Filter pore size & Filter type & Filter material & $\begin{array}{l}\text { Number of } \\
\text { filters used }\end{array}$ & $\begin{array}{l}\text { Filter area } \\
\left(\mathrm{cm}^{3}\right)\end{array}$ & $\begin{array}{l}\text { Volume } \\
\text { filtered } \\
\text { (L) }\end{array}$ & $\begin{array}{l}\text { Retentate } \\
\text { volume } \\
\text { (L) }\end{array}$ \\
\hline \multicolumn{7}{|c|}{ Well 1587} \\
\hline $5.0 \mu \mathrm{m}$ & Poretics & Polycarbonate & 35 & 2,240 & 833 & 0.34 \\
\hline $0.45 \mu \mathrm{m}$ & Millipore & Polyvinylidene fluoride & 8 & 3,715 & 828 & 0.42 \\
\hline 100,000 Daltons & Millipore & Polyethersulfone & 8 & 3,715 & 825 & -- \\
\hline 10,000 Daltons & Millipore & Cellulose & 8 & 3,715 & 820 & 0.80 \\
\hline
\end{tabular}

SW-51

$\begin{array}{lllrrrr}5.0 \mu \mathrm{m} & \text { Poretics } & \text { Polycarbonate } & 14 & 896 & 300 & 0.30 \\ 0.45 \mu \mathrm{m} & \text { Millipore } & \text { Polyvinylidene fluoride } & 8 & 3,715 & 296 & 0.32 \\ 100,000 \text { Daltons } & \text { Millipore } & \text { Polyethersulfone } & 8 & 3,715 & 292 & 0.52 \\ 10,000 \text { Daltons } & \text { Millipore } & \text { Cellulose } & 8 & 3,715 & 287 & 0.62\end{array}$

SW-53

\begin{tabular}{lllllll}
$3.0 \mu \mathrm{m}$ & Balston & Glass fiber & 1 & -- & 120 & -- \\
$0.45 \mu \mathrm{m}$ & Millipore & Polyvinylidene fluoride & 6 & 2,786 & 116 & 1.36 \\
100,000 Daltons & Millipore & Polyethersulfone & 6 & 2,786 & 112 & 1.08 \\
10,000 Daltons & Millipore & Cellulose & 6 & 2,786 & 108 & 0.95 \\
\hline
\end{tabular}


Table 4. Protocols used for the resin extraction of the 10,000-Dalton filtrate of water from Well 1587 and surface-water sites SW-51 and SW-53

$\left[\mathrm{Cl}^{-}\right.$, chloride; $\mathrm{H}^{+}$, hydrogen; $\mathrm{NA}$, not applicable, - , no data]

\begin{tabular}{|c|c|c|c|c|c|c|}
\hline Resin type & $\begin{array}{l}\text { Extraction } \\
\text { mode }\end{array}$ & $\begin{array}{l}\text { Volume of } \\
10,000-D a l t o n \\
\text { filtrate } \\
\text { extracted } \\
\text { (liters) }\end{array}$ & $\begin{array}{c}\text { Volume of } \\
\text { post-XAD-8- } \\
\text { extracted } \\
10,000-\text { Dalton } \\
\text { filtrate } \\
\text { extracted } \\
\text { (liters) }\end{array}$ & $\begin{array}{l}\text { Mass of } \\
\text { resin used } \\
\text { (grams) }\end{array}$ & $\begin{array}{l}\text { Mass of fulvic } \\
\text { acid recovered } \\
\text { (milligrams) }\end{array}$ & $\begin{array}{c}\text { Fulvicacid } \\
\text { concentration } \\
\text { (milligrams pe } \\
\text { liter) }\end{array}$ \\
\hline \multicolumn{7}{|c|}{ Well 1547} \\
\hline Amberlite XAD-8 & Column & 417 & -- & - & 192 & 0.46 \\
\hline $\begin{array}{l}\text { Biorad AG1-X8 anion-exchange resin, } \\
100-200 \text { mesh, } \mathrm{Cl}^{-} \text {form }\end{array}$ & Batch & 100 & 100 & 80 & $\mathrm{NA}$ & -- \\
\hline $\begin{array}{l}\text { Biorad AG50W-X8 cation-exchange } \\
\text { resin, } 100-200 \text { mesh, } \mathrm{H}^{+} \text {form }\end{array}$ & Batch & 100 & 100 & 80 & NA & - \\
\hline \multicolumn{7}{|c|}{ SW-51 } \\
\hline Amberlite XAD-8 & Column & 150 & -- & - & 312 & 2.08 \\
\hline $\begin{array}{l}\text { Biorad AG1-X8 anion-exchange resin, } \\
100-200 \text { mesh, } \mathrm{Cl}^{-} \text {form }\end{array}$ & Batch & 100 & 100 & 80 & $\mathrm{NA}$ & -- \\
\hline $\begin{array}{l}\text { Biorad AG50W-X8 cation-exchange } \\
\text { resin, } 100-200 \text { mesh, } \mathrm{H}^{+} \text {form }\end{array}$ & Batch & 100 & 100 & 80 & NA & -- \\
\hline \multicolumn{7}{|c|}{ SW-53 } \\
\hline Amberlite XAD-8 & Column & 103 & - & - & 186 & 1.81 \\
\hline $\begin{array}{l}\text { Biorad AG1-X8 anion-exchange resin, } \\
100-200 \text { mesh, } \mathrm{Cl}^{-} \text {form }\end{array}$ & Batch & 100 & 100 & 80 & NA & $\cdots$ \\
\hline $\begin{array}{l}\text { Biorad AG50W-X8 cation-exchange } \\
\text { resin, } 100-200 \text { mesh, } \mathrm{H}^{+} \text {form }\end{array}$ & Batch & 100 & 100 & 80 & NA & -- \\
\hline
\end{tabular}


Table 5. Radiochemical analysis of field blanks: plutonium 239 and 240 [ $\mu \mathrm{m}$, micrometers; $\mathrm{pCi} / \mathrm{L}$, picocuries per liter, $\mathrm{pCi} /$ sample, picocuries per sample; $\mathrm{pCi} / \mathrm{gram}$, picocuries per gram]

\begin{tabular}{|c|c|c|c|c|}
\hline Sample & Result & Units & $\begin{array}{c}\text { Analytical } \\
\text { Error }\end{array}$ & $\begin{array}{l}\text { Detection } \\
\text { Limit }\end{array}$ \\
\hline \multicolumn{5}{|c|}{ Water blanks } \\
\hline Unfiltered deionized water & 0.001 & $\mathrm{pCi} / \mathrm{L}$ & 0.003 & 0.005 \\
\hline 5.0- $\mu \mathrm{m}$ filtered deionized water & 0.004 & $\mathrm{pCi} / \mathrm{L}$ & 0.004 & 0.005 \\
\hline $0.45-\mu \mathrm{m}$ filtered deionized water & 0.006 & $\mathrm{pCi} / \mathrm{L}$ & 0.004 & 0.007 \\
\hline 100,000-Dalton filtered deionized water & 0.001 & $\mathrm{pCi} / \mathrm{L}$ & 0.003 & 0.005 \\
\hline 10,000 -Dalton filtered deionized water & 0.006 & $\mathrm{pCi} / \mathrm{L}$ & 0.005 & 0.008 \\
\hline Post-XAD-8 10,000-Dalton filtered deionized water & 0.002 & $\mathrm{pCi} / \mathrm{L}$ & 0.004 & 0.005 \\
\hline Post anion-exchange resin 10,000-Dalton filtered deionized water & 0.004 & $\mathrm{pCi} / \mathrm{L}$ & 0.005 & 0.006 \\
\hline Post cation-exchange resin 10,000-Dalton filtered deionized water & 0.001 & $\mathrm{pCi} / \mathrm{L}$ & 0.003 & 0.006 \\
\hline \multicolumn{5}{|c|}{ Filter blanks } \\
\hline 5.0- $\mu \mathrm{m}$ filter (new) & 0.005 & pCi/sample & 0.013 & 0.025 \\
\hline $0.45-\mu \mathrm{m}$ filter (new) & 0.006 & pCi/sample & 0.008 & 0.008 \\
\hline 100,000-Dalton filter (new) & 0.003 & pCi/sample & 0.005 & 0.007 \\
\hline 10,000-Dalton filter (new) & 0.005 & pCi/sample & 0.010 & 0.018 \\
\hline \multicolumn{5}{|c|}{ Resin blanks } \\
\hline XAD-8 resin (new) & 0 & pCi/gram. & 0.05 & 0.08 \\
\hline Anion-exchange resin (new) & 0.001 & pCi/gram & 0.006 & 0.005 \\
\hline Cation-exchange resin (new) & 0.001 & $\mathrm{pCi} / \mathrm{gram}$ & 0.004 & 0.004 \\
\hline
\end{tabular}


Table 6. Radiochemical analysis of field blanks: americium 241

$[\mu \mathrm{m}$, micrometers; $\mathrm{pCi} / \mathrm{L}$, picocuries per liter, $\mathrm{pCi} /$ sample, picocuries per sample; $\mathrm{pCi} / \mathrm{gram}$, picocuries per gram]

\begin{tabular}{|c|c|c|c|c|}
\hline Sample & Result & Units & $\begin{array}{l}\text { Analytical } \\
\text { Error }\end{array}$ & $\begin{array}{l}\text { Detection } \\
\text { Limit }\end{array}$ \\
\hline \multicolumn{5}{|c|}{ Water blanks } \\
\hline Unfiltered deionized water & 0.002 & $\mathrm{pCi} / \mathrm{L}$ & 0.004 & 0.006 \\
\hline 5.0- $\mu \mathrm{m}$ filtered deionized water & 0.002 & $\mathrm{pCi} / \mathrm{L}$ & 0.004 & 0.007 \\
\hline $0.45-\mu \mathrm{m}$ filtered deionized water & 0.001 & $\mathrm{pCi} / \mathrm{L}$ & 0.004 & 0.009 \\
\hline 100,000-Dalton filtered deionized water & 0.001 & $\mathrm{pCi} / \mathrm{L}$ & 0.003 & 0.007 \\
\hline 10,000-Dalton filtered deionized water & 0.005 & $\mathrm{pCi} / \mathrm{L}$ & 0.003 & 0.006 \\
\hline Post-XAD-8 10,000-Dalton filtered deionized water & 0.002 & $\mathrm{pCi} / \mathrm{L}$ & 0.004 & 0.006 \\
\hline Post anion-exchange resin 10,000-Dalton filtered deionized water & 0.001 & $\mathrm{pCi} / \mathrm{L}$ & 0.003 & 0.007 \\
\hline Post cation-exchange resin 10,000-Dalton filtered deionized water & 0 & $\mathrm{pCi} / \mathrm{L}$ & 0.005 & 0.009 \\
\hline \multicolumn{5}{|c|}{ Filter blanks } \\
\hline 5.0- $\mu \mathrm{m}$ filter (new) & 0.008 & $\mathrm{pCi} / \mathrm{sample}$ & 0.011 & 0.010 \\
\hline $0.45-\mu \mathrm{m}$ filter (new) & 0.022 & $\mathrm{pCi} / \mathrm{sample}$ & 0.020 & 0.025 \\
\hline 100,000 -Dalton filter (new) & 0 & $\mathrm{pCi} /$ sample & 0.026 & 0.023 \\
\hline 10,000-Dalton filter (new) & 0.016 & $\mathrm{pCi} / \mathrm{sample}$ & 0.019 & 0.016 \\
\hline \multicolumn{5}{|c|}{ Resin blanks } \\
\hline XAD-8 resin (new) & 0 & pCi/gram & 0.02 & 0.06 \\
\hline Anion-exchange resin (new) & 0.002 & pCi/gram & 0.008 & 0.001 \\
\hline Cation-exchange resin (new) & 0.001 & $\mathrm{pCi} /$ gram & 0.004 & 0.007 \\
\hline
\end{tabular}


Table 7. Radiochemical analysis of field blanks: uranium 233 and 234

[ $\mu \mathrm{m}$, micrometers; $\mathrm{pCi} / \mathrm{L}$, picocuries per liter, $\mathrm{pCi} /$ sample, picocuries per sample; $\mathrm{pCi} / \mathrm{gram}$, picocuries per gram]

\begin{tabular}{|c|c|c|c|c|}
\hline Sample & Result & Units & $\begin{array}{c}\text { Analytical } \\
\text { Error }\end{array}$ & $\begin{array}{l}\text { Detectlon } \\
\text { Lmit }\end{array}$ \\
\hline \multicolumn{5}{|c|}{ Water blanks } \\
\hline Unfiltered deionized water & 0.22 & $\mathrm{pCi} / \mathrm{L}$ & 0.19 & 0.22 \\
\hline $5.0-\mu \mathrm{m}$ filtered deionized water & 0.088 & $\mathrm{pC} \mathbf{i} / \mathrm{L}$ & 0.13 & 0.16 \\
\hline $0.45-\mu \mathrm{m}$ filtered deionized water & 0.27 & $\mathrm{pCi} / \mathrm{L}$ & 0.23 & 0.30 \\
\hline 100,000 -Dalton filtered deionized water & 0.31 & $\mathrm{pCi} / \mathrm{L}$ & 0.24 & 0.36 \\
\hline 10,000-Dalton filtered deionized water & 0.23 & $\mathrm{pCi} / \mathrm{L}$ & 0.21 & 0.25 \\
\hline Post-XAD-8 10,000-Dalton filtered deionized water & 0.12 & $\mathrm{pCi} / \mathrm{L}$ & 0.20 & 0.22 \\
\hline Post anion-exchange resin 10,000-Dalton filtered deionized water & 0.18 & $\mathrm{pCi} / \mathrm{L}$ & 0.19 & 0.26 \\
\hline Post cation-exchange resin 10,000-Dalton filtered deionized water & 0.15 & $\mathrm{pCi} / \mathrm{L}$ & 0.25 & 0.20 \\
\hline \multicolumn{5}{|c|}{ Filter blanks } \\
\hline $5.0-\mu \mathrm{m}$ filter (new) & 0.022 & pCi/sample & 0.035 & 0.050 \\
\hline $0.45-\mu \mathrm{m}$ filter (new) & 0.007 & $\mathrm{pCi} /$ sample & 0.026 & 0.059 \\
\hline 100,000-Dalton filter (new) & 0.004 & pCi/sample & 0.024 & 0.064 \\
\hline 10,000-Dalton filter (new) & -0.004 & pCi/sample & 0.004 & 0.053 \\
\hline \multicolumn{5}{|c|}{ Resin blanks } \\
\hline XAD-8 resin (new) & 0 & pCi/gram & 0.03 & 0.12 \\
\hline Anion-exchange resin (new) & 0.003 & pCi/gram & 0.003 & 0.01 \\
\hline Cation-exchange resin (new) & 0.01 & pCi/gram & 0.04 & 0.08 \\
\hline
\end{tabular}




\section{Sample Analysis}

Filtrates, particle retentates, filters, resins, and algal samples were submitted to IT Laboratories, Richland, Washington, or to AEB Consultants, Pine Bluff, Arkansas, for radiochemical analysis. Plutonium 239 and 240, Am 241 , and $\mathrm{U} 233$ and 234 were analyzed by alpha isotopic separation, using an alpha spectrometric detector. Minimum detectable activities varied with sample type, amount of sample available for analysis, and detection efficiency. All analyses included yield tracers for verification of sample processing and counting efficiency.

Metals analysis by inductively coupled-plasma/atomic-emission spectrometry was done by NFT, Inc., Golden, Colorado. The analyses included standard reference samples. Detection limits for these analyses are listed in table 8. Anion analysis by ion chromatography (for $\mathrm{Cl}^{-}, \mathrm{F}^{-}$, and $\mathrm{SO}_{4}^{-}$) and acidimetric titration (for carbonate and bicarbonate) was done by Acculabs, Inc., Golden, Colorado. Detection limits for these analyses are listed in table 9. Organic-carbon analysis by high-temperature catalyzed combustion and electrophoretic mobility measurements by electrophoretic light scattering were done at USGS laboratories in Lakewood, Colorado. The detection limit for organic-carbon analysis by this procedure was $0.2 \mathrm{mg} / \mathrm{C} / \mathrm{L} .{ }^{13}$ Carbon NMR (nuclear magnetic resonance) spectra of fulvic-acid isolates were done at USGS laboratories in Reston, Virginia. Scanning-electron microscopy/ energy-dispersive X-ray analysis (SEM-EDX) on the particle retentates was done at the USGS electron-microscope laboratory in Lakewood, Colorado.

\section{RESULTS OF FILTRATION AND ANALYSES}

\section{Sample Integrity}

Critical to conclusions regarding the function of particle-mediated transport of radionuclides in natural water is the assurance that particles recovered by filtration are representative of in-situ particle population and are not simply post-collection artifacts. This study applied stringent sampling protocols to minimize perturbation of natural conditions during sampling and processing and monitored parameters relevant to sample integrity during collection and processing. To determine the success of these efforts, two principal criteria were set. First, no major deviations from in-situ values of solution chemistry and physical measurements should be measured from the time the sample is collected until the time that filtration is completed. Second, scanning-electron microscopic examination of retentates and filtrates, although qualitative, should indicate that the filtration was effective and that the recovered particles are not simply post-collection artifacts. Specifically, the presence of particles in the retentate smaller than the filter pore size would indicate that filter was clogged and that radionuclide association data would be biased in favor of larger particles. Conversely, the presence of particles in the filtrate larger than the filter pore size would indicate that either filter integrity was lost or that post-collection coagulation of particles had occurred. Loss of filter integrity would tend to bias the results in favor of smaller particles. Post-collection coagulation would result in bias in favor of larger particles. Field testing of filter integrity indicated no evidence that the filters were defective.

To assess sample integrity of the Well 1587 sample, $\mathrm{pH}$ and specific conductance of the filtrates were monitored during filtration (table 10). During the course of a total processing time of 38 hours, four measurements each were made on the stored unfiltered sample, the $5.0-\mu \mathrm{m}$ filtrate, the $0.45-\mu \mathrm{m}$ filtrate, the 100,000 -Dalton filtrate, and the 10,000-Dalton filtrate. The $\mathrm{pH}$ of the stored unfiltered sample varied little with time (range 7.65 to 7.69 ) (table 10), indicating that the maintenance of a $\mathrm{N}_{2} / \mathrm{CO}_{2}$ atmosphere throughout the sample was effective in preventing $\mathrm{CO}_{2}$ degassing of the sample. Minimal $\mathrm{pH}$ variation with time was measured in the $5.0-\mu \mathrm{m}$, $0.45-\mu \mathrm{m}, 100,000$-Dalton, and 10,000-Dalton filtrates, indicating that $\mathrm{CO}_{2}$ degassing was similarly controlled in the stored filtrates of intermediate filtration steps by the application of a $\mathrm{N}_{2} / \mathrm{CO}_{2}$ atmosphere. As the sample moved through the filter sequence, however, there was an increase in filtrate $\mathrm{pH}$. At 20 minutes, for example, the $\mathrm{pH}$ of 
Table 8. Detection limits for inductively coupled plasma/ atomic-emission spectrometry analysis

\begin{tabular}{lc}
\hline Analyte & $\begin{array}{c}\text { Detection limit } \\
\text { (micrograms per liter) }\end{array}$ \\
\hline Aluminum & 50 \\
Arsenic & 2 \\
Barium & 20 \\
Calcium & 1,000 \\
Iron & 20 \\
Lithium & 10 \\
Magnesium & 1,000 \\
Manganese & 10 \\
Potassium & 1,000 \\
Silicon & 100 \\
Sodium & 1,000 \\
Strontium & 5 \\
Vanadium & 10 \\
Zinc & 10 \\
\hline
\end{tabular}

Table 9. Detection limits for anion analyses

\begin{tabular}{lc}
\hline \multicolumn{1}{c}{ Analyte } & $\begin{array}{c}\text { Detection limit } \\
\text { (milligrams per liter) }\end{array}$ \\
\hline Bicarbonate & 5 \\
Carbonate & 5 \\
Fluoride & 0.5 \\
Chloride & 3 \\
Sulfate & 5 \\
Nitrate and nitrite & 0.1 \\
\hline
\end{tabular}


Table 10. Specific-conductance and $\mathrm{pH}$ measurements made during the course of ultrafiltration of water from Well 1587 water collected at the Rocky Flats Plant

[ $\mu \mathrm{m}$, micrometer, Well 1587 sample: Total processing time $=38$ hours]

\begin{tabular}{|c|c|c|c|c|c|}
\hline Elapsed time & Unfiltered & $5.0-\mu \mathrm{m}$ filtrate & $0.45-\mu \mathrm{m}$ filtrate & $\begin{array}{l}\text { 100,000-Dalion } \\
\text { filitrate }\end{array}$ & $\begin{array}{l}\text { 10,000-Dalton } \\
\text { filtrate }\end{array}$ \\
\hline \multicolumn{6}{|c|}{ Specific conductance (microseimens) } \\
\hline 45 minutes & 424 & 422 & 425 & 425 & 426 \\
\hline 3 hours & 425 & 419 & 424 & 424 & 423 \\
\hline 23 hours & 424 & 424 & 425 & 426 & 425 \\
\hline 37 hours & 422 & 425 & 422 & 424 & 424 \\
\hline \multicolumn{6}{|c|}{ pH } \\
\hline 20 minutes & 7.66 & 7.70 & 7.75 & 7.82 & 8.08 \\
\hline 3 hours & 7.65 & 7.69 & 7.77 & 7.84 & 8.04 \\
\hline 23 hours & 7.68 & 7.73 & 7.79 & 7.84 & 8.09 \\
\hline 37 hours & 7.69 & 7.70 & 7.80 & 7.86 & 8.13 \\
\hline
\end{tabular}

filtrates increased along the filtration sequence from 7.66 for the unfiltered sample to 8.08 for the 10,000-Dalton filtrate (table 10). Similar increases were measured after 3 hours, 23 hours, and 37 hours. These measurements indicate that, although degassing of $\mathrm{CO}_{2}$ was effectively prevented during sample acquisition and storage, degassing did occur during filtration.

Analysis of $5-\mu \mathrm{m}, 0.45-\mu \mathrm{m}$, and 100,000-Dalton retentate samples by scanning-electron microscopy (SEM) revealed apparent aggregation, although if these particles were formed in the retentate during filtration or in the process of preparation for SEM examination was not certain. The extent of particle-size alteration is not known, but would be expected to bias the particle-size distribution toward larger particles and, therefore, bias radioisotope association results toward larger particles. The measured alteration of $\mathrm{pH}$ during filtration underscores the need for the entire sample collection, filtration, and processing sequence to be isolated from the atmosphere for ground-water samples.

In contrast to $\mathrm{pH}$, specific conductance (table 10) did not vary as the sample moved through the filtration sequence. Because dissolved-ionic species account for most of the charge that is measured as specific conductance, there seemed to be no measurable retention of major dissolved species.

The $\mathrm{pH}$ of water from seeps SW- 51 and SW-53 remained relatively unchanged during storage and filtration, indicating that the samples were at equilibrium with atmospheric $\mathrm{CO}_{2}$ on collection (table 11). The $\mathrm{pH}$ stability indicates that physical agitation during filtration, and not chemical reactions between the sample and the filter medium, was responsible for the $\mathrm{pH}$ increase of the filtrates from Well 1587. 
Table 11. Measurements of $\mathrm{pH}$ made during the course of ultrafiltration of water from surface-water sites SW-51 and SW-53

[ $\mu \mathrm{m}$, micrometer, $\mathrm{pH}$, in standard units SW-51 sample: total processing time $=16$ hours; SW-53 sample: total processing time $=9$ hours]

\begin{tabular}{|c|c|c|c|c|c|}
\hline Elapsed time & Unfiltered & 5.0- $\mu \mathrm{m}$ filtrate ${ }^{1}$ & $0.45-\mu \mathrm{m}$ filtrate & $\begin{array}{c}\text { 100,000-Daiton } \\
\text { filtrate }\end{array}$ & $\begin{array}{l}\text { 10,000-Dalton } \\
\text { filtrate }\end{array}$ \\
\hline \multicolumn{6}{|c|}{$\mathrm{pH}$ in SW-51 sample } \\
\hline 1 hour & 7.73 & 7.74 & 7.75 & 7.75 & 7.74 \\
\hline 7 hours & 7.75 & 7.73 & 7.76 & 7.74 & 7.76 \\
\hline 14 hours & 7.73 & 7.74 & 7.74 & 7.72 & 7.73 \\
\hline \multicolumn{6}{|c|}{$\mathrm{pH}$ in SW-53 sample } \\
\hline 1 hour & 7.54 & 7.56 & 7.53 & 7.54 & 7.53 \\
\hline 4 hours & 7.58 & 7.54 & 7.55 & 7.54 & 7.52 \\
\hline 8 hours & 7.54 & 7.55 & 7.54 & 7.55 & 7.53 \\
\hline
\end{tabular}

13.0- $\mu \mathrm{m}$ filtrate for $S W-53$.

Scanning electron microscope (SEM) examination of retentates from the surface-water samples, however, indicated some evidence of post-collection aggregation, although to a lesser extent than the Well 1587 sample. The processes of retentate concentration and preparation of the sample for SEM analysis can affect apparent particle sizes and argues for in-line filtration for the acquisition of SEM samples.

\section{Particle Recovery}

Three considerations are critical to assessing the potential of particle-facilitated transport of radionuclides in natural water. First, the particles must be present in sufficient quantity to have a significant effect on transport. Second, the particles must be reactive with the contaminant of concern. Third, the particles must be mobile under the physiochemical conditions of the flow regime. The first consideration, detailing particle recovery from water from the three sites, is included in table 12. For Well 1587, a total of $833 \mathrm{~L}$ of water was collected and filtered. By summing the particle concentration of each size fraction, the particle concentration of the whole-water sample was calculated to be $1.32 \mathrm{mg} / \mathrm{L}$ (table 12). Nine percent of the total particle mass was recovered in the particulate phase; 91 percent of the total particle mass was present in the three colloidal phases. For seep SW-51, 300 L of water was collected and filtered. The particle concentration of the whole-water sample was about $3 \mathrm{mg} / \mathrm{L}$ (table 12). Eighteen percent of the total particle mass was recovered in the particulate phase; about 82 percent of the total particle mass was present in the three colloidal phases.

For SW-53, $120 \mathrm{~L}$ of water was collected and filtered. The particle concentration of the whole water sample was calculated to be about $100 \mathrm{mg} / \mathrm{L}$. Eighty-two percent of the total particle mass was recovered in the particulate phase; 18 percent of the particle mass was present in the three colloidal phases. 
Table 12. Particle recovery from filtration of water from Well 1587 and surface-water sites SW-51 and SW-53 [mm, micrometer; >, greater than; <, less than]

\begin{tabular}{|c|c|c|c|c|c|}
\hline Phase & Size & $\begin{array}{l}\text { Volume filtered } \\
\text { (liters) }\end{array}$ & $\begin{array}{l}\text { Particle mass } \\
\text { recovered } \\
\text { (milligrams) }\end{array}$ & $\begin{array}{c}\text { Particle } \\
\text { concentration } \\
\text { (milligrams per } \\
\text { liter) }\end{array}$ & $\begin{array}{l}\text { Percent of total } \\
\text { particle mass in } \\
\text { phase }\end{array}$ \\
\hline \multicolumn{6}{|c|}{ Well 1587} \\
\hline Particulate & $>5.0 \mu \mathrm{m}$ & 833 & 103 & 0.12 & 9 \\
\hline Colloid & $0.45 \mu \mathrm{m}-5.0 \mu \mathrm{m}$ & 828 & 169 & 0.20 & 16 \\
\hline Colloid & 100,000 Daltons $-0.45 \mu \mathrm{m}$ & 825 & 302 & 0.37 & 28 \\
\hline Colloid & 10,000 Daltons $-100,000$ Daltons & 820 & 515 & 0.63 & 47 \\
\hline Total & & & 1,089 & ${ }^{1} 1.31$ & 100 \\
\hline \multicolumn{6}{|c|}{ SW.51 } \\
\hline Particulate & $>5.0 \mu \mathrm{m}$ & 300 & 161 & 0.54 & 18 \\
\hline Colloid & $0.45 \mu \mathrm{m}-5.0 \mu \mathrm{m}$ & 296 & 137 & 0.46 & 16 \\
\hline Colloid & 100,000 Daltons $-0.45 \mu \mathrm{m}$ & 292 & 238 & 0.82 & 27 \\
\hline Colloid & 10,000 Daltons $-100,000$ Daltons & 287 & 338 & 1.18 & 39 \\
\hline Total & & & 874 & $1_{2.91}$ & 100 \\
\hline \multicolumn{6}{|c|}{ SW-53 } \\
\hline Particulate & $>3.0 \mu \mathrm{m}$ & 120 & 9,840 & 82.00 & 82 \\
\hline Colloid & $0.45 \mu \mathrm{m}-3.0 \mu \mathrm{m}$ & 116 & 943 & 8.13 & 8 \\
\hline Colloid & 100,000 Daltons $-0.45 \mu \mathrm{m}$ & 112 & 641 & 5.72 & 5 \\
\hline Colloid & 10,000 Daltons $-100,000$ Daltons & 108 & 546 & 5.06 & 5 \\
\hline Total & & & 11,970 & 199.75 & 100 \\
\hline
\end{tabular}

${ }^{1}$ Totals for particle concentration may not sum due to rounding error. 
The particle-recovery data indicated the disparate aquatic environments from which the samples were collected. The sample from Well 1587 was typical of most ground water in that the concentration of particulate species was low. The flowing surface water at site SW-51, which was in contact with bed sediments and terrestrial vegetation, carried about triple the particulate and colloid concentration of the ground water. The relatively slow flowing water of the wetland environment at site SW-53, which had extensive aquatic-plant populations, contained particulate concentrations about two orders of magnitude greater than the ground water. In the low-particulate water of Well 1587 and site SW-51,colloids were the predominant phase. In the wetland water at site SW-53, colloids seem to compose a smaller percentage of the total particle concentration, although particles of 3 to $5 \mu \mathrm{m}$ were defined as particulates in this sample, and therefore created a bias toward underestimation of colloid concentrations in this sample. Colloids existed at much higher concentrations in water from SW-53 than from Well 1587 and SW-51. Therefore, at all of the sites, colloids existed in potentially sufficient quantity to facilitate the transport of radionuclides.

\section{Inorganic Chemistry}

The results of the analysis of the unfiltered and filtered water samples for inorganic species are listed in table 13. These samples are enriched in $\mathrm{Ca}$ and $\mathrm{Mg}$, compared to $\mathrm{Na}$, which indicates the geologic setting. The ${ }^{-}$ higher $\mathrm{Ca}$ concentrations are consistent with the measurement of calcite in the particle fractions in the initial study (Harnish and others, 1994). For all the major cations, the dissolved species were the predominant form. This result is similar to the result from the initial study (Hamish and others, 1994).

The dissolved inorganic species detected in the unfiltered samples from SW-53 are listed in table 13. For SW-51, only $\mathrm{Al}, \mathrm{Fe}$, and $\mathrm{Ba}$ had concentrations greater than the detection limit and, for Well 1587, only $\mathrm{Al}$ and $\mathrm{Ba}$ were detected in the unfiltered sample. This pattern can be explained by the much greater abundance of particles in the water sample from SW-53. The Al concentration detected in the sample from Well 1587 was essentially unchanged by filtration, indicating that the $\mathrm{Al}$ was truly dissolved.

For the sample from SW-51, the $\mathrm{Al}$ and $\mathrm{Fe}$ concentrations were decreased substantially by the first filtration through the 5.0- $\mu \mathrm{m}$ filter (table 13). This result indicated that the particulates from these two sites may contain hydrous $\mathrm{Al}$ and $\mathrm{Fe}$ oxides. Such oxides would have surfaces with the capability to sorb radionuclides.

The association of trace metals with the particulate and colloidal fractions was more complicated for the sample from SW-53. Aluminum and the trace metals that had low concentrations in the unfiltered samples $(\mathrm{Zn}, \mathrm{As}$, and $\mathrm{V}$ ) were removed by the first $(3-\mu \mathrm{m})$ filtration step (table 13). The decreases in $\mathrm{Al}$ and Fe concentrations at the first filtrate were greater than tenfold, but the decrease in Mn was only about fourfold. This result indicated that the SW-53 particulates were possibly enriched in hydrous $\mathrm{Al}, \mathrm{Fe}$, and $\mathrm{Mn}$ oxides.

Measurable concentrations of Fe were in the 3- $\mu \mathrm{m}$ filtrate (table 13), but the next filtration step decreased concentrations to undetectable values. In contrast, dissolved $\mathrm{Mn}$ was not decreased to undetectable levels even by the final 10,000-Dalton filtration step. These results indicated that the colloids between 3 and $0.45 \mu \mathrm{m}$ may contain hydrous Fe oxides and that the colloid fractions likely did not contain substantial concentrations of Mn oxides. It is not known why Mn concentrations increased in the 100,000-Dalton and 10,000-Dalton filtrates at site SW-53. 


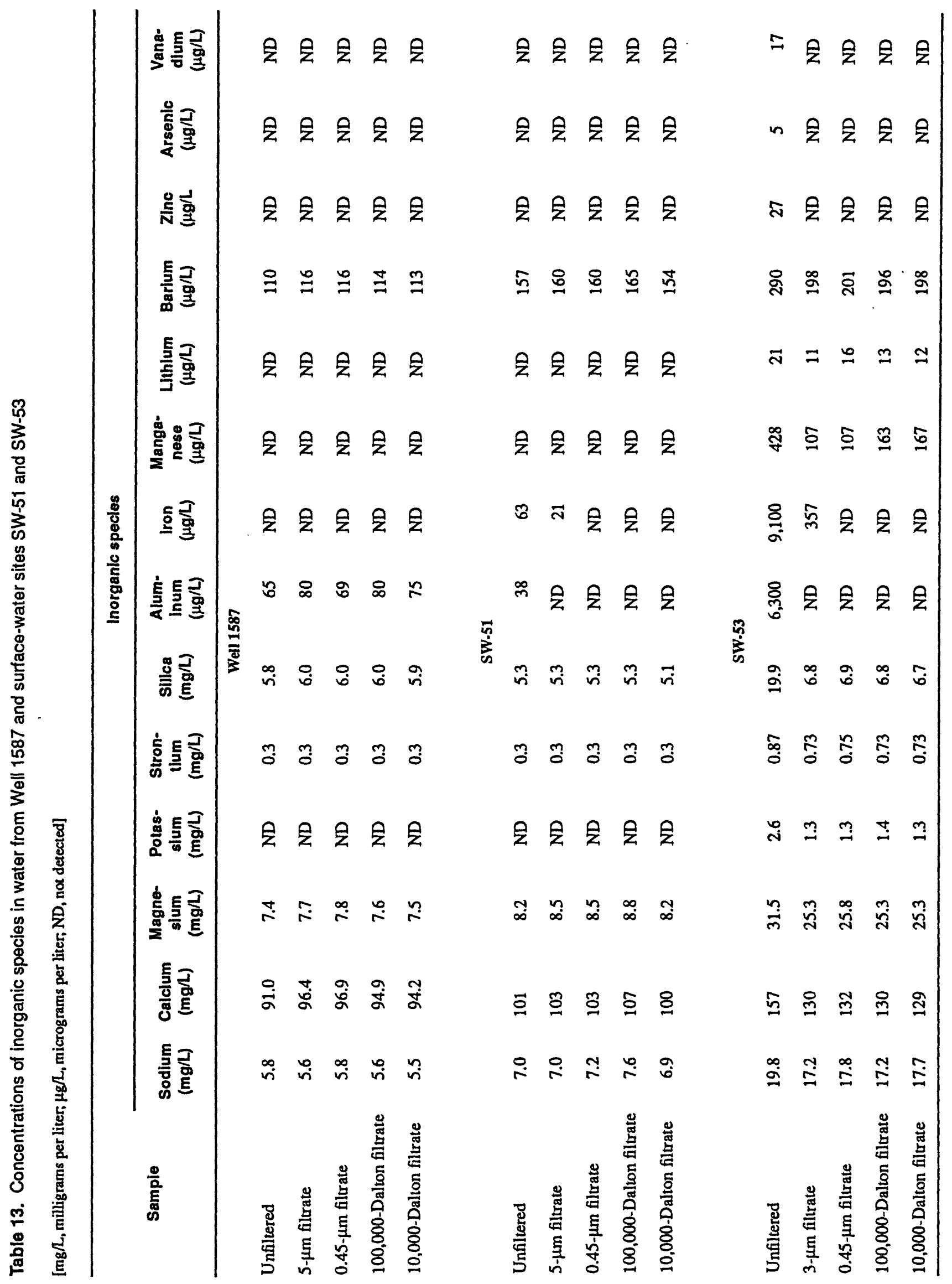




\section{Radiochemical Analyses}

\section{Filtrate Analysis}

Results of radiochemical analyses of unfiltered samples and filtrate samples of ground water from Well 1587 and surface water from sites SW-51 and SW-53 are listed in table 14 and are reported in picocuries per liter. Plutonium 239 and 240 were detected in all unfiltered samples and filtrate samples from all three sites, and the highest activity concentrations were detected in the unfiltered samples (table 14). Total (unfiltered) concentrations were highest in the surface-water samples from SW-51 and SW-53 (about 1.45 and $4.14 \mathrm{pCi} / \mathrm{L}$ ); the concentration was about $0.26 \mathrm{pCi} / \mathrm{L}$ in the water from Well 1587. Plutonium 239 and 240 concentration activities were significantly lower in the 5- $\mu \mathrm{m}$ and 3- $\mu \mathrm{m}$ filtrates and in subsequent filtrates. These results indicated that $\mathrm{Pu}$ is particlereactive, preferentially associating with the particulate size fraction in these water samples. More than 92 percent of the $\mathrm{Pu} 239$ and 240 concentration in the Well 1587 sample was associated with the particulate fraction greater than $5 \mu \mathrm{m}$. Similarly, 80 percent of the Pu 239 and 240 activity in the SW-51 sample and 79 percent of the Pu 239 and 240 activity in the SW-53 sample were associated with the particulate fraction. The only colloid fractions that compose a substantial part of total Pu 239 and 240 activity were the 0.45 - to 3- $\mu \mathrm{m}$ fraction from SW-53 where about 20 percent of total concentration was associated with this fraction.

The unfiltered concentration of about $0.26 \mathrm{pCi} / \mathrm{L}$ in water from Well 1587 was an order of magnitude greater than the concentration $(0.0235 \mathrm{pCi} / \mathrm{L})$ measured in the November 1991 sampling of the same well (Harnish and others, 1994). This disparity may be due to mobilization of Pu by the greater infiltration rate and shear forces that could detach Pu-bearing particles from aquifer solids or surface soils prior to infiltration of water in the spring rainy season. Altematively, the disparity may be due to the difficulty of obtaining representative samples in systems containing large particles and particle-reactive contaminants. Large particles are less likely to be uniformly distributed in the sample; and, thus, a single sampling of a water for a particle-associated species is less likely to be representative of mean concentration of that species. Americium 241 concentrations in the filtrates from the three sites were generally near or less than detection limits (table 14). No interpretation of size-distribution association was possible. Uranium 233 and 234 were detected in the unfiltered and filtrate samples from all three sites (table 14), and the uniformity of concentrations in all of the fractions indicated that most of the $U 233$ and 234 in these samples was in the dissolved phase.

\section{Particle Analysis}

Results of radiochemical analysis of the dried retentates from the three samples and of the grab samples of algae obtained at sites SW-51 and SW-53 are listed in table 15. These concentrations are a measure of the extent of reactivity of each particle-size fraction with Pu 239 and 240, Am 241, and $U 233$ and 234. The data do not indicate relative abundances of particles among the size fractions and, thus, are not a measure of the contribution of each size fraction to total radionuclide load in the water. The mass of the recovered particulate fraction and the largest colloid fraction from SW-53 are from a 3- $\mu \mathrm{m}$ filter and are not directly comparable to the same fractions collected at the other two sample sites.

Plutonium 239 and 240 activities associated with the particulate fractions were remarkably consistent among the three sample sites (about 7.25, 7.68, and $8.23 \mathrm{pCi} / \mathrm{g}$ for Well 1587, SW-51, and SW-53) (table 15). Plutonium activities associated with the colloidal fractions, however, indicated considerable variation among these sites. The largest colloidal fraction ( 0.45 to $5 \mu \mathrm{m}$ for SW-51 and 0.45 to $3 \mu \mathrm{m}$ for SW-53) was associated with the highest Pu 239 and 240 activity concentrations in samples from SW-51 and SW-53 (28.05 and $23.33 \mathrm{pCi} / \mathrm{g}$ ). Plutonium activity in the Well 15870.45 - to $5-\mu \mathrm{m}$ colloidal fraction was much lower $(2.23 \mathrm{pCi} / \mathrm{g})$. The sample from $S W-51$ had high $\mathrm{Pu}$ activities for the two smaller colloid fractions $(10.72 \mathrm{pCi} / \mathrm{g}$ for the 100,000 -Dalton to $0.45-\mu \mathrm{m}$ fraction 
Table 14. Results of radiochemical analysis of water from Well 1587 and surface-water sites SW- 51 and SW-53 [pCi/L, picocuries per liter; $\mu \mathrm{m}$, micrometer, ND, not detected]

\begin{tabular}{|c|c|c|c|}
\hline \multirow{2}{*}{ Sample } & \multicolumn{3}{|c|}{$\begin{array}{l}\text { Activity } \\
\text { (pCi/L) }\end{array}$} \\
\hline & Pu 239 and 240 & Am 21 & $U 233$ and 234 \\
\hline \multicolumn{4}{|c|}{ Well 1587} \\
\hline Unfiltered & $0.26 \pm 0.02$ & $0.015 \pm 0.006$ & $0.74 \pm 0.07$ \\
\hline $5-\mu \mathrm{m}$-filtrate & $0.02 \pm 0.01$ & ND & $0.79 \pm 0.07$ \\
\hline $0.45-\mu \mathrm{m}$ filtrate & $0.02 \pm 0.01$ & ND & $0.39 \pm 0.06$ \\
\hline 100,000-Dalton filtrate & $0.02 \pm 0.01$ & ND & $0.71 \pm 0.07$ \\
\hline 10,000 -Dalton filtrate & $0.01 \pm 0.002$ & ND & $0.55 \pm 0.05$ \\
\hline \multicolumn{4}{|c|}{ SW-51 } \\
\hline Unfiltered & $1.45 \pm 0.05$ & ND & $1.02 \pm 0.09$ \\
\hline 5 - $\mu \mathrm{m}$-filtrate & $0.29 \pm 0.02$ & $0.04 \pm 0.01$ & $1.34 \pm 0.10$ \\
\hline $0.45-\mu \mathrm{m}$ filtrate & $0.20 \pm 0.03$ & $0.02 \pm 0.01$ & $1.30 \pm 0.19$ \\
\hline 100,000-Dalton filtrate & $0.12 \pm 0.01$ & $0.07 \pm 0.01$ & $1.16 \pm 0.10$ \\
\hline 10,000 -Dalton filtrate & $0.06 \pm 0.001$ & ND & $1.32 \pm 0.12$ \\
\hline \multicolumn{4}{|c|}{ SW-53 } \\
\hline Unfiltered & $4.14 \pm 0.13$ & ND & $1.43 \pm 0.12$ \\
\hline $3-\mu \mathrm{m}$-filtrate & $0.86 \pm 0.05$ & ND & $1.63 \pm 0.12$ \\
\hline $0.45-\mu \mathrm{m}$ filtrate & $0.05 \pm 0.02$ & ND & $2.11 \pm 0.43$ \\
\hline 100,000 -Dalton filtrate & $0.04 \pm 0.01$ & ND & $1.39 \pm 0.09$ \\
\hline 10,000 -Dalton filtrate & $0.03 \pm 0.01$ & ND & $1.50 \pm 0.27$ \\
\hline
\end{tabular}


Table 15. Results of radiochemical analysis of dried retentates and algal samples recovered in the filtration of water from Well 1587 and surface-water sites SW-51 and SW-53

[Pu, plutonium; Am, americium; U, uranium; $\mu \mathrm{m}$, micrometer, $\mathrm{pCi} / \mathrm{g}$, picocuries per gram; ND, not detected; >, greater than; --, no data]

\begin{tabular}{|c|c|c|c|c|}
\hline \multirow[t]{2}{*}{ Phase } & \multirow[t]{2}{*}{ Size } & \multicolumn{3}{|c|}{$\begin{array}{l}\text { Activity } \\
\text { (pCl/g) }\end{array}$} \\
\hline & & Pu 239 and 240 & Am 241 & U 233 and 234 \\
\hline \multicolumn{5}{|c|}{ Well 1587} \\
\hline Particulate & $>5 \mu \mathrm{m}$ & $7.25 \pm 1.99$ & $1.34 \pm 0.82$ & ND \\
\hline Colloid & $0.45 \mu \mathrm{m}-5 \mu \mathrm{m}$ & $2.23 \pm 0.74$ & $0.54 \pm 0.38$ & ND \\
\hline Colloid & 100,000 Daltons $-0.45 \mu \mathrm{m}$ & -- & -- & - \\
\hline Colloid & 10,000 Daltons - 100,000 Daltons & $1.07 \pm 0.32$ & $0.31 \pm 0.17$ & $0.98 \pm 0.77$ \\
\hline \multicolumn{5}{|c|}{ SW.51 } \\
\hline Particulate & $>5 \mu \mathrm{m}$ & $7.68 \pm 0.93$ & $11.45 \pm 2.59$ & $5.44 \pm 4.15$ \\
\hline Colloid & $0.45 \mu \mathrm{m}-5 \mu \mathrm{m}$ & $28.05 \pm 4.32$ & $5.44 \pm 1.67$ & $5.27 \pm 5.10$ \\
\hline Colloid & 100,000 Daltons $-0.45 \mu \mathrm{m}$ & $10.72 \pm 1.65$ & $3.10 \pm 0.89$ & $2.83 \pm 2.17$ \\
\hline Colloid & 10,000 Daltons - 100,000 Daltons & $13.09 \pm 1.98$ & $0.89 \pm 0.38$ & $2.20 \pm 1.93$ \\
\hline Algae $^{1}$ & & $12.79 \pm 0.76$ & $2.78 \pm 0.22$ & $0.38 \pm 0.15$ \\
\hline \multicolumn{5}{|c|}{ SW.53 } \\
\hline Particulate & $>3 \mu \mathrm{m}$ & $8.23 \pm 0.40$ & $1.81 \pm 1.02$ & $0.10 \pm 0.04$ \\
\hline Colloid & $0.45 \mu \mathrm{m}-3 \mu \mathrm{m}$ & $23.33 \pm 2.41$ & $3.49 \pm 0.59$ & $2.99 \pm 1.29$ \\
\hline Colloid & 100,000 Daltons $-0.45 \mu \mathrm{m}$ & $0.53 \pm 0.22$ & $0.38 \pm 0.17$ & $2.89 \pm 1.75$ \\
\hline Colloid & 10,000 Daltons - 100,000 Daltons & $0.34 \pm 0.18$ & $0.09 \pm 0.08$ & $3.19 \pm 1.43$ \\
\hline Algae $^{1}$ & & $1.13 \pm 0.13$ & $0.38 \pm 0.09$ & ND \\
\hline
\end{tabular}

\footnotetext{
${ }^{1}$ Grab sample.
} 
and $13.09 \mathrm{pCi} / \mathrm{g}$ for the 10,000 - to 100,000 -Dalton fraction). Plutonium activities in colloidal samples from SW-53 were considerably lower $(0.53 \mathrm{pCi} / \mathrm{g}$ for the 100,000 -Dalton to $0.45-\mu \mathrm{m}$ fraction and $0.34 \mathrm{pCi} / \mathrm{g}$ for the 10,000- to 100,000-Dalton fraction). For the Well 1587 sample, no data were available for the 100,000-Dalton to $0.45-\mu \mathrm{m}$ fraction. The $10,000-$ to $100,000-\mathrm{Dalton}$ fraction contained $1.07 \mathrm{pCi} / \mathrm{g} \mathrm{Pu} 239$ and 240 . The difference in activity between the two smaller colloidal fractions of SW-51 and the two smaller colloidal fractions of SW-53 is particularly striking. Reactivity with $\mathrm{Pu}$ is not simply a function of particle size, but involves other physiochemical characteristics of the colloids.

The algal samples collected from seeps SW-51 and SW-53 differed by an order of magnitude in associated Pu 239 and 240 activity (12.79 pCi/g at SW-51 and 1.13 pCi/g at SW-53) (table 15). Although based on a limited sample, this result indicates that association with algal material may be an important sink for Pu 239 and 240 in the surface water and that the magnitude of algal reactivity with $\mathrm{Pu} 239$ and 240 is variable.

Distribution of Am 241 activities among the particle-size fractions at the three sites were more variable than $\mathrm{Pu} 239$ and 240 activities; the highest activities were in the particulate and the largest colloid fraction. The highest Am 241 activity (11.45 pCi/g) was measured in the particulate fraction of the sample from SW-51 (table 15). As with $\mathrm{Pu}, \mathrm{Am}$ activities in the two smaller colloid fractions from SW-51 were considerably higher than the activities in the two smaller colloid fractions collected at SW-53. This measurement indicated that the same physiochemical characteristics that determined the particle reactivity of these colloid fractions with Pu 239 and 240 affected their reactivity with Am 241. Americium activities of the algal samples from SW-51 and SW-53 (2.78 pCi/g for $\mathrm{SW}-51 ; 0.38 \mathrm{pCi} / \mathrm{g}$ for SW-53) indicated a similar difference in relative reactivity as compared to Pu, and similar conclusions can be drawn regarding their potential role as sinks for Am.

Uranium 233 and 234 activity distribution among the size fractions differ for samples from SW-51 and SW-53. In the sample from SW-51, highest activities were in the particulate and largest colloid fraction (table 15). In the sample from SW-53, U 233 and 234 , activities were low $(0.10 \mathrm{pCi} / \mathrm{g})$ in the particulate sample. The three colloidal fractions in SW-53 had similar concentrations (about $3 \mathrm{pCi} / \mathrm{g}$ ) that were much higher concentrations than the particulate sample. Uranium 233 and 234 were detected at $0.38 \mathrm{pCi} / \mathrm{g}$ in the algal sample from SW-51 and were not detected in the SW-53 sample, indicating that algae have limited reactivity with U 233 and 234 in the water and would not be expected to affect transport substantially. The error terms associated with these analyses are high, and the $U 233$ and 234 concentrations associated with the particles were two to three orders of magnitude lower than the activities measured in the dissolved phase as described in the following sections of the report.

\section{Particle and Filter Analysis}

The contribution of particles to the transport and fate of radionuclides depends on their reactivity with the radionuclide of interest and on the quantity of particles present. Calculated results of radiochemical analysis of retentates, filters used in the isolation of these particles, and the dissolved phase collected from the three samples are listed in tables 16-18. Activity concentrations, in units of picocuries per liter, reflect the activity in picocuries per gram of the isolated retentates (table 15) and particles retained on the filters, and the concentration of particles in a size fraction (milligrams per liter) (table 12). Dissolved-phase concentrations were determined directly for $\mathrm{Pu}$ 239 and 240 and for $U 233$ and 234 . Filters were ashed and analyzed in the same manner as the isolated retentates. The percent of whole-water actinide activity attributed to particles in the size fraction is compared with the percent of whole-water particle mass present in the size fraction (tables 16-18), except for the data from Well 1587 (table 16) where lack of activity data for the 100,000 -Dalton to $0.45-\mu \mathrm{m}$ fraction precluded calculation of activity percentages. Americium 241 was not detected in the filtrates by direct analysis, and reported dissolved Am concentrations are the sum of anion- and cation-exchange-resin extraction of the final filtrate. Because no yield tracer was used in these extractions, complete recovery of Am 241 was not assured. Reported activities for the dissolved concentration activity of Am 241 may underestimate environmental activities. 
Table 16. Results of radiochemical analysis of recovered retentates, particles adhering to filters, and dissolved phase in water from Well 1587

[Pu, plutonium; Am, americium; U, uranium; $\mathrm{pCi} / \mathrm{L}$, picocuries per liter, $\mu \mathrm{m}$, micrometer, ND, not detected; >, greater than; <, less than; --, no data]

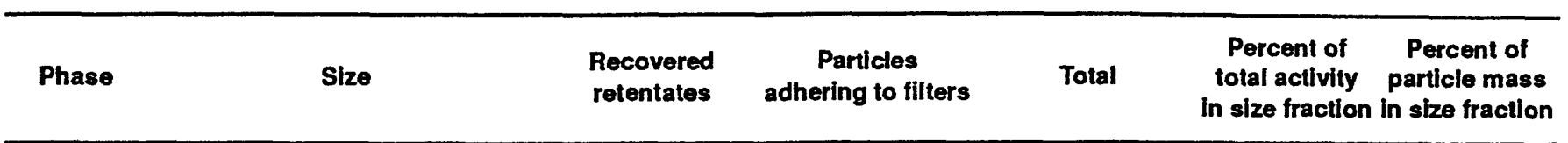

\begin{tabular}{|c|c|c|c|c|c|c|}
\hline \multicolumn{7}{|c|}{$\begin{array}{l}\text { Pu } 239 \text { and } 240 \text { Activity } \\
\text { (pCVL) }\end{array}$} \\
\hline Particulate & $>5 \mu \mathrm{m}$ & $8.70 \mathrm{E}-4 \pm 2.39 \mathrm{E}-4$ & 2.88E-5土3.50E-6 & $8.99 E-4 \pm 2.43 E-4$ & -- & 9 \\
\hline Colloid & $0.45 \mu \mathrm{m}-5 \mu \mathrm{m}$ & 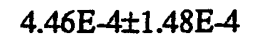 & $3.45 \mathrm{E}-4 \pm 5.50 \mathrm{E}-6$ & $7.91 \mathrm{E}-4 \pm 1.54 \mathrm{E}-4$ & -- & 16 \\
\hline Colloid & 100,000 -Daltons $-0.45 \mu \mathrm{m}$ & -- & $7.75 \mathrm{E}-5 \pm 1.24 \mathrm{E}-5$ & $7.75 \mathrm{E}-5 \pm 1.24 \mathrm{E}-5$ & -- & 28 \\
\hline Colloid & 10,000 -Daltons - 100,000-Daltons & $6.74 \mathrm{E}-4 \pm 2.02 \mathrm{E}-4$ & $1.10 \mathrm{E}-5 \pm 2.10 \mathrm{E}-6$ & $6.85 \mathrm{E}-4 \pm 2.04 \mathrm{E}-4$ & -- & 47 \\
\hline Dissolved & $<10,000$-Daltons & & & ${ }^{1} 1.20 \mathrm{E}-2 \pm 2.0 \mathrm{E}-3$ & -- & \\
\hline Total & & $1.99 \mathrm{E}-3 \pm 5.89 \mathrm{E}-4$ & $4.60 \mathrm{E}-4 \pm 2.35 \mathrm{E}-5$ & $1.52 \mathrm{E}-2 \pm 2.61 \mathrm{E}-3$ & -- & 100 \\
\hline \multicolumn{7}{|c|}{$\begin{array}{c}\text { Am } 241 \text { Activity } \\
(\mathrm{pC} / \mathrm{L})\end{array}$} \\
\hline Particulate & $>5 \mu \mathrm{m}$ & $1.61 \mathrm{E}-4 \pm 9.84 \mathrm{E}-5$ & $2.82 \mathrm{E}-5 \pm 2.63 \mathrm{E}-5$ & $1.89 \mathrm{E}-4 \pm 1.25 \mathrm{E}-4$ & -- & 9 \\
\hline Colloid & $0.45 \mu \mathrm{m}-5 \mu \mathrm{m}$ & $1.08 \mathrm{E}-4 \pm 7.60 \mathrm{E}-5$ & $3.32 \mathrm{E}-5 \pm 1.87 \mathrm{E}-5$ & $1.41 \mathrm{E}-4 \pm 9.47 \mathrm{E}-5$ & $\cdots$ & 16 \\
\hline Colloid & 100,000 -Daltons $-0.45 \mu \mathrm{m}$ & - & $1.05 \mathrm{E}-5 \pm 4.30 \mathrm{E}-6$ & $1.05 \mathrm{E}-5 \pm 4.30 \mathrm{E}-6$ & -- & 28 \\
\hline Colloid & 10,000 -Daltons - 100,000-Daltons & $1.95 \mathrm{E}-4 \pm 1.07 \mathrm{E}-4$ & $1.02 \mathrm{E}-5 \pm 9.40 \mathrm{E}-6$ & $2.97 \mathrm{E}-4 \pm 1.16 \mathrm{E}-4$ & $\cdots$ & 47 \\
\hline Dissolved & $<10,000$-Daltons & & & $29.59 \mathrm{E}-4 \pm 5.66 \mathrm{E}-4$ & -- & \\
\hline \multicolumn{7}{|l|}{ Total } \\
\hline \multicolumn{7}{|c|}{$\begin{array}{c}\mathrm{U} 233 \text { and234 } \\
(\mathrm{pCV} / \mathrm{L})\end{array}$} \\
\hline Particulate & $>5 \mu \mathrm{m}$ & ND & $2.49 \mathrm{E}-4 \pm 1.02 \mathrm{E}-4$ & $2.49 \mathrm{E}-4 \pm 1.02 \mathrm{E}-4$ & $\cdots$ & 9 \\
\hline Colloid & $0.45 \mu \mathrm{m}-5 \mu \mathrm{m}$ & ND & ND & ND & -- & 16 \\
\hline Colloid & 100,000 -Daltons $-0.45 \mu \mathrm{m}$ & - & ND & ND & -- & 28 \\
\hline Colloid & 10,000 -Daltons - 100,000-Daltons & $6.17 \mathrm{E}-4 \pm .85 \mathrm{E}-4$ & ND & $6.17 \mathrm{E}-4 \pm 4.85 \mathrm{E}-4$ & -- & 47 \\
\hline Dissolved & $<10,000$-Daltons & & & $15.50 \mathrm{E}-1 \pm 1.32 \mathrm{E}-2$ & -- & \\
\hline Total & & $6.17 \mathrm{E}-4 \pm .4 .85 \mathrm{E}-4$ & $2.49 \mathrm{E}-4 \pm 1.02 \mathrm{E}-4$ & $5.51 \mathrm{E}-1 \pm 1.38 \mathrm{E}-2$ & -- & 100 \\
\hline
\end{tabular}

${ }^{1}$ Direct analysis of less than 10,000-Dalton filtrate.

2 Sum of anion- and cation-exchange resin extraction of less than 10,000-Dalton filtrate 
The calculated distribution of the actinides Pu 239 and 240, Am 241, and U 233 and 234 among particle-size fractions for the Well 1587 water ispresented in table 16. The total activity of each of the actinides was underestimated for the 100,000 -Dalton to $0.45-\mu \mathrm{m}$ colloid fraction because of lack of activity data for the isolated retentates of this fraction. With this caveat, Pu 239 and 240 activity seems to be distributed primarily in the dissolved fraction. Despite the finding that colloids compose about 91 percent of the total particle concentration in the ground water, only a small part of the total Pu activity is associated with colloidal particles. Americium 241 activity is distributed mainly in the dissolved phase. As with $\mathrm{Pu}, \mathrm{Am} 241$ association with colloids is small compared to the abundance of colloids in the sample, and dissolved forms of Am are substantial. Uranium 233 and 234 are associated almost exclusively with the dissolved phase. The association of $U 233$ and 234 with particulates and colloids is negligible.

The results indicate that, although colloids in the water sample from Well 1587 compose a high percentage of total particle concentration, their effect on the actinide distribution is minimal unless the 100,000-Dalton to 0.45 - $\mu \mathrm{m}$ colloidal fraction is an important contributor to the total sample concentration. Dissolved-phase associations are important for all of the measured actinides, and $\mathrm{Pu} 239$ and 240 associate substantially with particulates.

The activity distributions of the actinides in the surface-water sample from SW-51 are listed in table 17. Plutonium 239 and 240 activity percentages are more evenly distributed among particulates, colloids, and the dissolved phase in SW-51 as compared to Well 1587, and a substantial fraction (40 percent) of total Pu activity is in the colloidal particles. Particulates are associated with 28 percent, and the dissolved phase with 32 percent of total sample activity of Pu 239 and 240. Americium 241 has a similar pattern; colloids account for 47 percent of total sample activity, and particulates and dissolved associations are 33 percent and 20 percent. The distribution pattern for U 233 and 234 in SW-51 is similar to the pattern for Well 1587. Negligible activity percentages are associated with the particulate and colloidal particles (considerably less than 1 percent for each phase). More than 99 percent of total sample activity is in the dissolved phase. Compared to the results from Well 1587, colloids are substantially more important for Pu 239 and 240 and for Am 241 reactivity in the sample from SW-51.

Distribution patterns of the actinides among particle and dissolved phases for the surface-water sample from SW-53 are listed in table 18. Particle concentrations in this surface water are much higher $(100 \mathrm{mg} / \mathrm{L})$ than in water from Well 1587 and SW-51, and the percentage of total particle concentration represented by colloids is much lower (19 percent). At SW-53, particulates predominate the particle pool, composing 81 percent of the total particle concentration. Plutonium 239 and 240 activity is concentrated in the particulate fraction (73 percent of total activity), and in the colloidal fraction ( 25 percent of total activity). The largest colloidal fraction ( 0.45 to $3 \mu \mathrm{m})$ accounts for almost all of the colloid-associated activity, although its percentage of particle concentration (8 percent) is only slightly higher than those of the two smaller colloidal fractions. At SW-53, then, the abundant particulates and large colloids are especially reactive with Pu 239 and 240. Dissolved-phase associations of Pu 239 and 240 are extremely low on a percentage basis in SW-53 (3 percent of total sample activity) compared to Well 1587 (53 percent) and SW-51 (32 percent) although the activity concentration of Pu 239 and 240 is intermediate between the Pu 239 activity concentration in the other two samples. The Am 241 distribution pattern is remarkably similar to the Pu distribution pattern. Americium 241 activity is concentrated in the particulate fraction ( 69 percent of total sample activity) and in the colloidal fraction (29 percent of total activity). As with Pu, the largest colloidal fraction accounts for almost all of the colloid-associated activity. At SW-53, particulates and large colloids are especially reactive with Am 241 and are especially abundant. Dissolved-phase associations of Am 241 are extremely low in SW-53 (1 percent of total sample activity) compared to Well 1587 (64 percent) and SW-51 (20 percent).

Distribution patterns of U 233 and 234 at SW-53 are similar to the patterns at Well 1587 and SW-51. Most of the total activity is in the dissolved fraction ( 96 percent), although the particulate and colloidal fraction contribution (4 percent) is slightly higher at SW-53 than at the other two sites. 
Table 17. Results of radiochemical analysis of recovered retentates, particles adhering to filters, and dissolved phase in water from surface-water site SW-51

[Pu, plutonium; Am, americium; U, uranium; $\mathrm{pCi} / \mathrm{L}$, picocuries per liter, $\mu \mathrm{m}$, micrometer, ND, not detected; >, greater than; $<$, less than; -, no data]

\begin{tabular}{|c|c|c|c|c|c|c|}
\hline Phase & Size & $\begin{array}{l}\text { Recovered } \\
\text { retentates }\end{array}$ & $\begin{array}{c}\text { Particles } \\
\text { adhering to filters }\end{array}$ & Total & $\begin{array}{c}\text { Percent of } \\
\text { total activity } \\
\text { in size fraction }\end{array}$ & $\begin{array}{l}\text { Percent of } \\
\text { particle mass } \\
\text { in size fractlon }\end{array}$ \\
\hline \multicolumn{7}{|c|}{$\begin{array}{l}\text { Pu } 239 \text { and } 240 \text { Activity } \\
(\mathrm{pC} / \mathrm{L})\end{array}$} \\
\hline Particulate & $>5 \mu \mathrm{m}$ & 4.15E-2士4.97E-3 & $9.54 \mathrm{E}-3 \pm 1.43 \mathrm{E}-3$ & $5.10 \mathrm{E}-2 \pm 6.40 \mathrm{E}-3$ & 28 & 18 \\
\hline Colloid & $0.45 \mu \mathrm{m}-5 \mu \mathrm{m}$ & $1.29 \mathrm{E}-2 \pm 1.01 \mathrm{E}-3$ & $1.20 \mathrm{E}-2 \pm 1.12 \mathrm{E}-3$ & $2.49 \mathrm{E}-2+3.13 \mathrm{E}-3$ & 14 & 16 \\
\hline Colloid & 100,000 -Daltons $-0.45 \mu \mathrm{m}$ & 8.79E-3土1.35E-3 & $1.27 \mathrm{E}-2 \pm 7.60 \mathrm{E}-3$ & $2.15 \mathrm{E}-2+8.95 \mathrm{E}-3$ & 12 & 27 \\
\hline Colloid & 10,000 -Daltons - 100,000-Daltons & $1.54 \mathrm{E}-2+2.30 \mathrm{E}-3$ & $1.11 \mathrm{E}-2 \pm 6.63 \mathrm{E}-4$ & $2.65 \mathrm{E}-2+2.96 \mathrm{E}-3$ & 14 & 39 \\
\hline Dissolved & $<10,000$-Daltons & -- & - & ${ }^{1} 5.90 \mathrm{E}-2 \pm 8.26 \mathrm{E}-3$ & 32 & - \\
\hline Total & & $7.86 \mathrm{E}-2 \pm 1.06 \mathrm{E}-2$ & $4.53 \mathrm{E}-2 \pm 1.08 \mathrm{E}-2$ & $1.83 \mathrm{E}-1 \pm 2.97 \mathrm{E}-2$ & 100 & 100 \\
\hline \multicolumn{7}{|c|}{$\begin{array}{l}\text { Am } 241 \text { Activity } \\
(p C l / L)\end{array}$} \\
\hline Particulate & $>5 \mu \mathrm{m}$ & $6.18 \mathrm{E}-3 \pm 1.39 \mathrm{E}-3$ & $1.21 \mathrm{E}-3 \pm 1.27 \mathrm{E}-4$ & $7.39 \mathrm{E}-3 \pm 1.52 \mathrm{E}-3$ & 33 & 18 \\
\hline Colloid & $0.45 \mu \mathrm{m}-5 \mu \mathrm{m}$ & $2.50 \mathrm{E}-3 \pm 7.73 \mathrm{E}-4$ & $2.63 \mathrm{E}-3 \pm 2.60 \mathrm{E}-4$ & $5.13 \mathrm{E}-3 \pm 1.03 \mathrm{E}-3$ & 23 & 16 \\
\hline Colloid & 100,000 -Daltons $-0.45 \mu \mathrm{m}$ & $2.54 \mathrm{E}-3 \pm 7.24 \mathrm{E}-4$ & $1.31 \mathrm{E}-3 \pm 1.70 \mathrm{E}-4$ & $3.85 \mathrm{E}-3 \pm 8.94 \mathrm{E}-4$ & 17 & 27 \\
\hline Colloid & 10,000 -Daltons - 100,000 -Daltons & $1.05 \mathrm{E}-3 \pm 4.41 \mathrm{E}-4$ & $6.44 \mathrm{E}-4 \pm 1.10 \mathrm{E}-5$ & $1.69 \mathrm{E}-3 \pm 4.52 \mathrm{E}-4$ & 7 & 39 \\
\hline Dissolved & $<10,000$-Daltons & -- & - & $24.56 \mathrm{E}-3 \pm 6.45 \mathrm{E}-4$ & 20 & \\
\hline Total & & $1.23 \mathrm{E}-2 \pm 3.33 \mathrm{E}-3$ & $5.79 \mathrm{E}-3 \pm 5.68 \mathrm{E}-4$ & $2.26 \mathrm{E}-2 \pm 4.54 \mathrm{E}-3$ & 100 & 100 \\
\hline \multicolumn{7}{|c|}{$\begin{array}{l}\text { U } 233 \text { and } 234 \\
(\mathrm{pCV} / \mathrm{L})\end{array}$} \\
\hline Particulate & $>5 \mu \mathrm{m}$ & $2.94 \mathrm{E}-3 \pm 2.23 \mathrm{E}-3$ & $2.81 \mathrm{E}-4 \pm 1.98 \mathrm{E}-4$ & $3.22 \mathrm{E}-3 \pm 2.43 \mathrm{E}-3$ & $<1$ & 18 \\
\hline Colloid & $0.45 \mu \mathrm{m}-5 \mu \mathrm{m}$ & $2.42 \mathrm{E}-3 \pm 2.36 \mathrm{E}-3$ & $3.37 \mathrm{E}-4 \pm 1.21 \mathrm{E}-4$ & $2.76 \mathrm{E}-3 \pm 2.48 \mathrm{E}-3$ & $<1$ & 16 \\
\hline Colloid & 100,000 -Daltons - $0.45 \mu \mathrm{m}$ & $2.32 \mathrm{E}-3 \pm 1.77 \mathrm{E}-3$ & $5.64 \mathrm{E}-4 \pm 1.25 \mathrm{E}-4$ & $2.88 \mathrm{E}-3 \pm 1.90 \mathrm{E}-3$ & $<1$ & 27 \\
\hline Colloid & 10,000 -Daltons - 100,000 -Daltons & $2.60 \mathrm{E}-3 \pm 2.27 \mathrm{E}-3$ & $6.74 \mathrm{E}-4 \pm 4.07 \mathrm{E}-4$ & $3.27 \mathrm{E}-3 \pm 2.68 \mathrm{E}-3$ & $<1$ & 39 \\
\hline Dissolved & $<10,000$-Daltons & -- & - & ${ }^{1} 1.32 \mathrm{E}+0 \pm 1.20 \mathrm{E}-1$ & 99 & \\
\hline Total & & $1.03 \mathrm{E}-2 \pm 8.63 \mathrm{E}-3$ & $1.85 \mathrm{E}-3 \pm 8.51 \mathrm{E}-4$ & $1.33 \mathrm{E}+0 \pm 1.30 \mathrm{E}-1$ & 100 & 100 \\
\hline
\end{tabular}

\footnotetext{
${ }^{1}$ Direct analysis of less than 10,000-Dalton filtrate.

${ }^{2}$ Sum of anion- and cation-exchange resin extraction of less than 10,000-Dalton filtrate
} 
Table 18. Results of radiochemical analysis of recovered retentates, particles adhering to filters, and dissolved phase in water from surface-water site SW-53

[Pu, plutonium; Am, americium; U, uranium; $\mathrm{PCi} / \mathrm{L}$, picocuries per liter, $\mu \mathrm{m}$, micrometer, $N D$, not detected; $>$, greater than; $<$, less than; -, no data]

\begin{tabular}{|c|c|c|c|c|c|c|}
\hline Phase & Size & $\begin{array}{l}\text { Recovered } \\
\text { retentates }\end{array}$ & $\begin{array}{l}\text { Particles } \\
\text { adhering to filters }\end{array}$ & Total & $\begin{array}{c}\text { Percent of } \\
\text { total activity } \\
\text { in size fraction }\end{array}$ & $\begin{array}{c}\text { Percent of } \\
\text { particle mass } \\
\text { in size fraction }\end{array}$ \\
\hline \multicolumn{7}{|c|}{$\begin{array}{l}\text { Pu } 239 \text { and } 240 \text { Activity } \\
(\mathrm{pCi} / \mathrm{L})\end{array}$} \\
\hline Particulate & $>3 \mu \mathrm{m}$ & & ${ }^{3} 6.75 \mathrm{E}-1 \pm 3.30 \mathrm{E}-2$ & $6.75 \mathrm{E}-1 \pm 3.30 \mathrm{E}-2$ & 73 & 82 \\
\hline Colloid & $0.45 \mu \mathrm{m}-3 \mu \mathrm{m}$ & $1.89 \mathrm{E}-1 \pm 1.95 \mathrm{E}-2$ & $2.90 \mathrm{E}-2 \pm 1.29 \mathrm{E}-2$ & $2.18 \mathrm{E}-1 \pm 3.24 \mathrm{E}-2$ & 23 & 8 \\
\hline Colloid & 100,000 -Daltons - $0.45 \mu \mathrm{m}$ & $3.02 \mathrm{E}-3 \pm 1.27 \mathrm{E}-3$ & $1.66 \mathrm{E}-3 \pm 3.24 \mathrm{E}-4$ & $4.68 \mathrm{E}-3 \pm 1.59 \mathrm{E}-3$ & $<1$ & 5 \\
\hline Colloid & 10,000 -Daltons - 100,000 -Daltons & $1.72 \mathrm{E}-3 \pm 8.98 \mathrm{E}-4$ & $8.42 \mathrm{E}-4 \pm 2.81 \mathrm{E}-4$ & $2.56 \mathrm{E}-3 \pm 1.18 \mathrm{E}-3$ & $<1$ & 5 \\
\hline Dissolved & $<10,000$-Daltons & - & - & $13.10 \mathrm{E}-2 \pm 1.55 \mathrm{E}-2$ & 3 & \\
\hline Total & & $1.94 \mathrm{E}-1 \pm 2.17 \mathrm{E}-2$ & $7.07 \mathrm{E}-1 \pm 4.65 \mathrm{E}-2$ & $9.31 \mathrm{E}-1 \pm 8.37 \mathrm{E}-2$ & 100 & 100 \\
\hline \multicolumn{7}{|c|}{$\begin{array}{l}\text { Am } 241 \text { Activity } \\
(\mathrm{pCi} / \mathrm{L})\end{array}$} \\
\hline Particulate & $>3 \mu \mathrm{m}$ & & ${ }^{3} 1.49 \mathrm{E}-1 \pm 8.41 \mathrm{E}-2$ & $1.49 \mathrm{E}-1 \pm 8.41 \mathrm{E}-2$ & 69 & 82 \\
\hline Colloid & $0.45 \mu \mathrm{m}-3 \mu \mathrm{m}$ & $2.84 \mathrm{E}-2 \pm 4.39 \mathrm{E}-3$ & $3.17 \mathrm{E}-2 \pm 7.92 \mathrm{E}-3$ & $6.01 \mathrm{E}-2 \pm 1.23 \mathrm{E}-2$ & 28 & 8 \\
\hline Colloid & 100,000 -Daltons $-0.45 \mu \mathrm{m}$ & $2.15 \mathrm{E}-3 \pm 1.02 \mathrm{E}-3$ & ND & $2.15 \mathrm{E}-3 \pm 1.02 \mathrm{E}-3$ & 1 & 5 \\
\hline Colloid & 10,000 -Daltons - 100,000 -Daltons & 4.78E-4I4.52E-4 & $2.57 \mathrm{E}-4 \pm 2.36 \mathrm{E}-4$ & $7.3 \mathrm{E}-4 \pm 6.88 \mathrm{E}-4$ & $<1$ & 5 \\
\hline Dissolved & $<10,000$-Daltons & - & - & $23.05 \mathrm{E}-3 \pm 8.22 \mathrm{E}-4$ & 1 & \\
\hline \multirow[t]{2}{*}{ Total } & & $3.10 \mathrm{E}-2 \pm 5.86 \mathrm{E}-3$ & $1.81 \mathrm{E}-1 \pm 9.23 \mathrm{E}-2$ & $2.15 \mathrm{E}-1 \pm 9.89 \mathrm{E}-2$ & 100 & 100 \\
\hline & \multicolumn{6}{|c|}{$\begin{array}{l}\text { U } 233 \text { and } 234 \\
(\mathrm{pCC} / \mathrm{L})\end{array}$} \\
\hline Particulate & $>3 \mu \mathrm{m}$ & & $38.21 \mathrm{E}-3 \pm 3.06 \mathrm{E}-3$ & 8.21E-3 $3 \pm 3.06 \mathrm{E}-3$ & $<1$ & 82 \\
\hline Colloid & $0.45 \mu \mathrm{m}-3 \mu \mathrm{m}$ & $2.43 \mathrm{E}-2 \pm 1.05 \mathrm{E}-2$ & $5.36 \mathrm{E}-3 \pm 1.91 \mathrm{E}-3$ & $2.97 \mathrm{E}-2 \pm 1.19 \mathrm{E}-2$ & 2 & 8 \\
\hline Colloid & 100,000 -Daltons $-0.45 \mu \mathrm{m}$ & $1.65 \mathrm{E}-2 \pm 1.00 \mathrm{E}-2$ & $5.03 \mathrm{E}-4 \pm 1.05 \mathrm{E}-4$ & $1.70 \mathrm{E}-2 \pm 1.01 \mathrm{E}-2$ & 1 & 5 \\
\hline Colloid & 10,000-Daltons - 100,000-Daltons & $1.61 \mathrm{E}-2+1.44 \mathrm{E}-2$ & ND & $1.61 \mathrm{E}-2 \pm 1.44 \mathrm{E}-2$ & 1 & 5 \\
\hline Dissolved & $<10,000$-Daltons & - & -- & 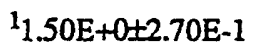 & 96 & \\
\hline
\end{tabular}

Total

$5.69 \mathrm{E}-2+3.49 \mathrm{E}-2 \quad 1.41 \mathrm{E}-2 \pm 5.08 \mathrm{E}-3 \quad 1.57 \mathrm{E}+0 \pm 3.09 \mathrm{E}-1 \quad 100$

100

\footnotetext{
${ }^{1}$ Direct analysis of less than 10,000 -Dalton filtrate.

${ }^{2}$ Sum of anion- and cation-exchange resin extraction of less than 10,000-Dalton filtrate.

${ }^{3}$ The total particle load of this fraction was retained on the filters.
} 


\section{Dissolved-Phase Associations with Fulvic Acid}

The concentrations of $\mathrm{Pu} 239$ and 240, Am 241, and U 233 in various dissolved phases for the three water samples are listed in tables 19-21. As described in the discussion of particle and filter analysis, the SW-53 sample had the greatest concentration of particulates, and most of the Pu 239 and 240 was associated with this particulate material. For the other two samples, the activity concentration of dissolved $\mathrm{Pu} 239$ and 240 was greater than that of the particulate $\mathrm{Pu} 239$ and 240. The total-dissolved Am 241 activity concentration was less than detection in all three samples. For all samples, most of the $U 233$ and 234 was in the dissolved phase.

The activity concentration of Pu 239 and 240 complexed by fulvic acid was calculated in two ways. In the first method of calculation (direct), the activity concentration of radionuclide in the isolated, lyopholized fulvic acid was multiplied by the fulvic-acid concentration. In the second method of calculation (difference), the anion and cation activity concentration were summed for the influent filtrate and the XAD-8 effluent. This sum represents an estimate of the dissolved activity concentration. Then, the fulvic acid associated actinide was calculated as the difference between the sum for the influent filtrate and the sum for the XAD-8 effluent. For Pu 239 and 240, the sum of the cation and anion activity is very close to the direct measurements of dissolved $\mathrm{Pu} 239$ and 240 ( 77 percent to 109 percent of the dissolved concentration). For Am 241, the dissolved activity concentration was less than detection, which is the reason for basing the second calculation on the sum of the cation and anion activity concentrations. The calculation by difference for $U 233$ and 234 resulted in comparable values to the direct calculation, but the values had a greater error.

For all three water samples, the two calculations for fulvic acid associated $\mathrm{Pu} 239$ and 240 produced very similar results, indicating that between 57 percent and 88 percent of the dissolved Pu 239 and 240 was complexed by fulvic acid. The similarity of the results of the two calculations indicates that the alteration of $\mathrm{pH}$ during the isolation procedure does not disrupt the fulvic-acid/Pu complexes. At the very high ligand to metal ratios in these samples, strong complexes would be predominant, and it is not surprising that these complexes would not be disrupted by $\mathrm{pH}$ alterations. The activity concentrations of Am 241 associated with the fulvic acid were very low, consistently two orders of magnitude lower than the concentrations of Pu 239 and 240 associated with fulvic acid. In contrast, the activity of fulvic-acid-bound $U$ in all three filtrates was larger than that for fulvic-acid-bound $\mathrm{Pu}$. The activity was, however, not as high a percentage of the total dissolved activity.

\section{Dissolved-Phase Anionic and Cationic Associations}

The 10,000-Dalton filtrates and the effluents from the XAD-8 resin were reacted with the anion- and cationexchange resins to further access the chemical speciation of the dissolved actinides. The results are presented in tables 19,20, and 21 and are summarized in table 22. A general pattern is evident. When the samples were reacted with the anion-exchange resin, most of the dissolved radionuclides were removed, whereas only small proportions of the radionuclides were removed by the cation-exchange resin. The finding that the cationic forms of all three radionuclides were consistently the fraction that had the least activity indicated that the dissolved radionuclides are not present as simple ions, such as $\mathrm{PuO}_{2}{ }^{+}$.

In the case of $\mathrm{Pu} 239$ and 240, these results are consistent with the previous result that the dissolved Pu 239 and 240 was complexed by fulvic acid. Fulvic acids are anionic at the near neutral $\mathrm{pH}$ of the samples and would have been sorbed by the anion-exchange resin. The results, therefore, can be explained by the sorption of fulvic acids containing complexed $\mathrm{Pu} 239$ and 240 and provide further support for the importance of fulvic-acid complexation of $\mathrm{Pu} 239$ and 240. However, for Am 241, the activity concentration removed by the anion-exchange resin is ten to twenty times greater than that associated with the fulvic acid. There are several possible explanations for this result. One explanation is that the dissolved Am 241 species are present as inorganic anions. Another explanation is that dissolved Am 241 is complexed by organic ligands that are not isolated as fulvic acid, such as more hydrophilic organic acids (Aiken and others, 1992). For $U 233$ and 234, the anionic activity concentration also is greater than the fulvic-acid-associated activity concentration, but not to as great an extent as for Am 241. The same two possible explanations also are applicable to this result. 
Table 19. Results of radiochemical analysis of less than 10,000-Dalton dissolved phase in water from Well 1587 for fulvic-acid, anionic, and cationic associations

[Pu, plutonium; Am, americium; U, uranium; ND, not detected; FAB, fulvic-acid bound; XAD-AEX, post-XAD 8 anion-exchange resin; AEX, anionexchange resin; XAD-CEX, post-XAD-8 cation-exchange resin; CEX, cation-exchange resin; $\mathrm{PC} /$; picocuries per liter]

\begin{tabular}{|c|c|c|c|}
\hline \multirow{2}{*}{ Sample } & \multicolumn{3}{|c|}{$\begin{array}{l}\text { Activity of sample } \\
\text { (PCI/L) }\end{array}$} \\
\hline & Pu 239 and 240 & Am 241 & U 233 and 234 \\
\hline Filtrate & $1.20 \mathrm{E}-2 \pm 2.00 \mathrm{E}-3$ & ND & $5.50 \mathrm{E}-1 \pm 1.32 \mathrm{E}-2$ \\
\hline $\mathrm{XAD}-8$ isolate $(\mathrm{FAB})^{1}$ & $7.45 \mathrm{E}-3 \pm 1.36 \mathrm{E}-3$ & 4.87E-5 5 6.13E- 6 & $5.09 \mathrm{E}-2 \pm 1.11 \mathrm{E}-2$ \\
\hline $\mathrm{XAD}-8$ isolate $(\mathrm{FAB})^{2}$ & $6.87 \mathrm{E}-3 \pm 1.63 \mathrm{E}-3$ & ND & $7.50 \mathrm{E}-2 \pm 6.76 \mathrm{E}-2$ \\
\hline & & & - \\
\hline Anion-exchangé resin (AEX) & $8.58 \mathrm{E}-3 \pm 9.61 \mathrm{E}-4$ & $9.08 \mathrm{E}-4 \pm 5.18 \mathrm{E}-4$ & $3.69 \mathrm{E}-1 \pm 2.84 \mathrm{E}-2$ \\
\hline Cation-exchange resin (CEX) & $5.95 \mathrm{E}-4 \pm 2.12 \mathrm{E}-4$ & $5.06 \mathrm{E}-5 \pm 4.80 \mathrm{E}-5$ & $8.20 \mathrm{E}-2+8.11 \mathrm{E}-3$ \\
\hline Total AEX and CEX & $9.18 \mathrm{E}-3 \pm 1.17 \mathrm{E}-3$ & $9.59 \mathrm{E}-4 \pm 5.66 \mathrm{E}-4$ & $4.51 \mathrm{E}-1 \pm 3.65 \mathrm{E}-2$ \\
\hline Post-XAD-8 anion-exchange resin (XAD-AEX) & $1.97 \mathrm{E}-3 \pm 3.34 \mathrm{E}-4$ & $7.96 \mathrm{E}-4 \pm 2.34 \mathrm{E}-4$ & $3.21 \mathrm{E}-1 \pm 2.43 \mathrm{E}-2$ \\
\hline Post XAD-8 cation-exchange resin (XAD-CEX) & $3.41 \mathrm{E}-4 \pm 1.22 \mathrm{E}-4$ & $3.94 \mathrm{E}-4 \pm 2.52 \mathrm{E}-4$ & $5.47 \mathrm{E}-2+6.83 \mathrm{E}-3$ \\
\hline Total FAB and XAD-AEX & $9.42 \mathrm{E}-3 \pm 1.69 \mathrm{E}-3$ & $8.45 \mathrm{E}-4 \pm 2.40 \mathrm{E}-4$ & $3.72 \mathrm{E}-1 \pm 3.54 \mathrm{E}-2$ \\
\hline
\end{tabular}

${ }^{1}$ Calculated directly from the activity of the XAD-8 isolate ('direct' calculation).

${ }^{2}$ Calculated by difference between the activity of anion- and cation-resin extraction of the 10,000-Dalton filtrate and the activity of post-XAd-8 anionand cation resin extraction of the 10,000-Dalton filtrate ('difference' calculation). 
Table 20. Results of radiochemical analysis of less than 10,000-Dalton dissolved phase in water from surface-water site SW-51 for fulvic-acid, anionic, and cationic associations

[Pu, plutonium; Am, americium; U, uranium; ND, not detected; FAB, fulvic-acid bound; XAD-AEX, post-XAD 8 anion-exchange resin; $A E X$, anionexchange resin; XAD-CEX, post-XAD-8 cation-exchange resin; CEX, cation-exchange resin; $\mathrm{PC} i /$; picocuries per liter]

\begin{tabular}{|c|c|c|c|}
\hline \multirow{2}{*}{ Sampie } & \multicolumn{3}{|c|}{$\begin{array}{l}\text { Activity of sample } \\
\text { (pCi/L) }\end{array}$} \\
\hline & Pu 239 and 240 & Am 241 & U 233 and 234 \\
\hline Filtrate & $5.90 \mathrm{E}-2 \pm 8.26 \mathrm{E}-3$ & ND & $1.32 \mathrm{E}+0 \pm 1.20 \mathrm{E}-1$ \\
\hline $\mathrm{XAD}-8$ isolate $(\mathrm{FAB})^{1}$ & $5.21 \mathrm{E}-2 \pm 5.88 \mathrm{E}-4$ & $2.26 \mathrm{E}-4 \pm 3.15 \mathrm{E}-5$ & $9.60 \mathrm{E}-2+2.30 \mathrm{E}-2$ \\
\hline $\mathrm{XAD}-8$ isolate $(\mathrm{FAB})^{2}$ & 4.97E-2+9.58E-3 & 4.77E-4 $\pm 1.96 \mathrm{E}-3$ & $1.23 \mathrm{E}-1 \pm 6.90 \mathrm{E}-2$ \\
\hline Anion-exchange resin (AEX) & $6.05 \mathrm{E}-2+3.25 \mathrm{E}-3$ & $4.46 \mathrm{E}-3 \pm 5.58 \mathrm{E}-4$ & $6.58 \mathrm{E}-1 \pm 4.83 \mathrm{E}-2$ \\
\hline Cation-exchange resin (CEX) & $9.97 \mathrm{E}-4 \pm 3.04 \mathrm{E}-4$ & $1.04 \mathrm{E}-4 \pm 8.72 \mathrm{E}-5$ & $3.34 \mathrm{E}-2 \pm 5.27 \mathrm{E}-3$ \\
\hline Total AEX and CEX & $6.15 \mathrm{E}-2+3.55 \mathrm{E}-3$ & $4.56 \mathrm{E}-3 \pm 6.45 \mathrm{E}-4$ & $6.91 \mathrm{E}-1 \pm 5.36 \mathrm{E}-2$ \\
\hline Post-XAD-8 anion-exchange resin (XAD-AEX) & $1.16 \mathrm{E}-2 \pm 5.88 \mathrm{E}-3$ & $3.93 \mathrm{E}-3 \pm 1.20 \mathrm{E}-3$ & $5.28 \mathrm{E}-1 \pm 4.12 \mathrm{E}-2$ \\
\hline Post XAD-8 cation-exchange resin (XAD-CEX) & $2.14 \mathrm{E}-4 \pm 1.46 \mathrm{E}-4$ & $1.53 \mathrm{E}-4 \pm 1.08 \mathrm{E}-4$ & $4.05 \mathrm{E}-2 \pm 5.49 \mathrm{E}-3$ \\
\hline Total FAB and XAD-AEX & $6.13 \mathrm{E}-2 \pm 6.47 \mathrm{E}-3$ & $4.16 \mathrm{E}-3 \pm 1.23 \mathrm{E}-3$ & $6.24 \mathrm{E}-1 \pm 6.42 \mathrm{E}-2$ \\
\hline
\end{tabular}

${ }^{1}$ Calculated directly from the activity of the XAD-8 isolate ('direct' calculation).

${ }^{2}$ Calculated by difference between the activity of anion- and cation-resin extraction of the 10,000-Dalton filtrate and the activity of post-XAD-8 anionand cation resin extraction of the 10,000-Dalton filtrate ('difference' calculation). 
Table 21. Results of radiochemical analysis of less than 10,000-Dalton dissolved phase in water from surface-water site SW-53 for fulvic-acid, anionic, and cationic associations

[Pu, plutonium; Am, americium; U, uranium; ND, not detected; FAB, fulvic-acid bound; XAD-AEX, post-XAD 8 anion-exchange resin; $A E X$, anion-exchange resin; XAD-CEX, post-XAD-8 cation-exchange resin; $C E X$, cation-exchange resin; $\mathrm{PCi} / \mathrm{L}$; picocuries per liter]

\begin{tabular}{lccc}
\hline \multicolumn{1}{c}{ Sample } & \multicolumn{3}{c}{$\begin{array}{c}\text { Activity of sample } \\
\text { (pCiL) }\end{array}$} \\
\cline { 2 - 4 } & Pu 239 and 240 & Am 241 & U 233 and 234 \\
\hline Filtrate & $3.10 \mathrm{E}-2 \pm 1.55 \mathrm{E}-2$ & $\mathrm{ND}$ & $1.50 \mathrm{E}+0 \pm 2.70 \mathrm{E}-1$ \\
XAD-8 isolate (FAB) ${ }^{1}$ & $2.29 \mathrm{E}-2 \pm 5.12 \mathrm{E}-3$ & $2.92 \mathrm{E}-4 \pm 4.93 \mathrm{E}-5$ & $1.66 \mathrm{E}-1 \pm 9.24 \mathrm{E}-2$ \\
XAD-8 isolate (FAB) & & & \\
& $2.30 \mathrm{E}-2 \pm 4.53 \mathrm{E}-3$ & $2.65 \mathrm{E}-4 \pm 2.15 \mathrm{E}-3$ & $2.32 \mathrm{E}-1 \pm 1.60 \mathrm{E}-1$ \\
& & & \\
Anion-exchange resin (AEX) & & & \\
Cation-exchange resin (CEX) & $3.23 \mathrm{E}-2 \pm 3.26 \mathrm{E}-3$ & $2.89 \mathrm{E}-3 \pm 7.14 \mathrm{E}-4$ & $1.01 \mathrm{E}+0 \pm 7.29 \mathrm{E}-2-$ \\
Total AEX and CEX & $1.45 \mathrm{E}-3 \pm 2.92 \mathrm{E}-4$ & $1.57 \mathrm{E}-4 \pm 1.08 \mathrm{E}-4$ & $8.76 \mathrm{E}-2 \pm 1.21 \mathrm{E}-3$ \\
& $3.38 \mathrm{E}-2 \pm 3.55 \mathrm{E}-3$ & $3.05 \mathrm{E}-3 \pm 8.22 \mathrm{E}-4$ & $1.10 \mathrm{E}+0 \pm 7.41 \mathrm{E}-2$ \\
Post-XAD-8 anion-exchange resin (XAD-AEX) & & & \\
Post XAD-8 cation-exchange resin (XAD-CEX) & $1.02 \mathrm{E}-2 \pm 7.83 \mathrm{E}-4$ & $2.68 \mathrm{E}-3 \pm 1.27 \mathrm{E}-3$ & $7.97 \mathrm{E}-1 \pm 6.41 \mathrm{E}-2$ \\
Total FAB and XAD-AEX & $5.65 \mathrm{E}-4 \pm 1.98 \mathrm{E}-4$ & $1.02 \mathrm{E}-4 \pm 5.98 \mathrm{E}-5$ & $6.83 \mathrm{E}-2 \pm 2.15 \mathrm{E}-2$ \\
\hline
\end{tabular}

'Calculated directly from the activity of the XAD-8 isolate ('direct' calculation).

${ }^{2}$ Calculated by difference between the activity of anion- and cation-resin extraction of the 10,000-Dalton filtrate and the activity of post-XAD-8 anionand cation resin extraction of the 10,000-Dalton filtrate ('difference' calculation).. 
Table 22. Summary of fulvic acid, anionic, and cationic-association ratios of actinides in the less than 10,000-Dalton dissolved phase in waer from Well 1587 and surface-water sites SW-51 and SW-53

[Pu, plutonium; Am, americium; U, uranium; ND, not detected; FAB, fulvic-acid bound; AEX, anion-exchange resin: XAD-AEX, post-XAD-8 anion-exchange resin]]

Ratio of activity in specifled fraction to total dissolved activity

\begin{tabular}{ccc}
\hline Pu 239 and 240 & Am 241 & U 233 and 234 \\
\hline Well 1587 & & \\
${ }^{3} 0.81^{4}(0.62)$ & ${ }^{3} 0.05^{4}(\mathrm{ND})$ & ${ }^{3} 0.11^{4}(0.09)$ \\
${ }^{3} 0.75^{4}(0.57)$ & ${ }^{3} 0.13^{4}(\mathrm{ND})$ & ${ }^{3} 0.17^{4}(0.14)$ \\
${ }^{3} 0.93^{4}(0.71)$ & ${ }^{3} 0.95^{4}(\mathrm{ND})$ & ${ }^{3} 0.82^{4}(0.67)$ \\
${ }^{3} 0.07^{4}(0.05)$ & ${ }^{3} 0.05^{4}(\mathrm{ND})$ & ${ }^{3} 0.18^{4}(0.15)$ \\
0.91 & 1.07 & 0.99
\end{tabular}

SW-51

FAB activity (direct) 1

${ }^{3} 0.85^{4}(0.88)$

${ }^{3} 0.05^{4}(\mathrm{ND})$

${ }^{3} 0.14^{4}(0.07)$

FAB activity (difference) $)^{2}$

${ }^{3} 0.81^{4}(0.84)$

${ }^{3} 0.11{ }^{4}(\mathrm{ND})$

${ }^{3} 0.18^{4}(0.09)$

Anionic activity

${ }^{3} 0.98^{4}(1.03)$

${ }^{3} 0.98{ }^{4}(\mathrm{ND})$

${ }^{3} 0.95^{4}(0.50)$

Cationic activity

${ }^{3} 0.02^{4}(0.02)$

${ }^{3} 0.02{ }^{4}(\mathrm{ND})$

${ }^{3} 0.05^{4}(0.03)$

AEX/total (FAB and XAD-AEX)

0.95

1.07

1.05

SW-53

FAB activity (direct) $)^{1}$

${ }^{3} 0.68^{4}(0.74)$

${ }^{3} 0.10^{4}(\mathrm{ND})$

${ }^{3} 0.15^{4}(0.11)$

FAB activity (difference) ${ }^{2}$

${ }^{3} 0.68^{4}(0.74)$

${ }^{3} 0.09{ }^{4}(\mathrm{ND})$

${ }^{3} 0.21^{4}(0.15)$

Anionic activity

${ }^{3} 0.96^{4}(1.04)$

${ }^{3} 0.95{ }^{4}(\mathrm{ND})$

${ }^{3} 0.92^{4}(0.67)$

Cationic activity

${ }^{3} 0.04^{4}(0.05)$

${ }^{3} 0.05^{4}(\mathrm{ND})$

${ }^{3} 0.08^{4}(0.06)$

AEX/total (FAB and XAD-AEX)

0.98

0.97

1.05

${ }^{1}$ Calculated directly from activity of XAD-8 isolate (fulvic acid) (FAB ${ }^{1}$ on tables 19-21).

${ }^{2}$ Calculated by difference between activity of anion-and cation-resin extraction of the 10,000-Dlton filtrate and activity of post XAD-8 anion-and cation-resin extraction of the 10,000-Dalton filtrate (FAB ${ }^{2}$ on tables 19-21).

${ }^{3}$ Calculated using the sum of anion-and cation-resin extraction of 10,000-Dalton filtrate (total AEX and CEX on tables 19-21).

${ }^{4}$ Calculated using direct analysis of 10,000-Dalton filtrate (filtrate on tables 19-21). 
The results of the anion- and cation-exchange treatment of the effluent from the XAD-8 column also are listed in tables 19,20,21,22, and 23. As presented in table 23, one general result for all radionuclides and all three samples is that the anionic activity concentration of the original filtrate is reasonably close (between 91 percent and 107 percent) of the sum of the fulvic-acid activity concentration and the post-XAD-8 anionic-activity concentration. This result supports the interpretation that radionuclides complexed by fulvic acid are removed as anions in the anion-exchange treatment. Much of the dissolved Pu 239 and 240 was sorbed by the XAD-8 resin, and the activity concentration in the anionic fraction after XAD-8 treatment was about 16 to 33 percent of the activity concentration of the original filtrate. However, for Am 241 and $U 233$ and 234, the post XAD-8 anionic activity concentration was a larger part of the anionic activity concentration in the original filtrate. The result that the anionic Am 241 and $\mathrm{U} 233$ and 234 were not sorbed on the XAD-8 column is consistent with their speciation being predominated by inorganic anions or by complexes that had organic ligands more hydrophilic than fulvic acids.

Table 23. Ratios of anionic activity concentrations to the sum of the fulvic-acid-bound activity concentration and the anionic activity concentration after XAD-8 treatment of samples.

[AEX, anion-exchange resin, FAB, fulvic-acid bound; XAD-AEX, post-XAD-8 anion-exchange resin; Pu, plutonium;

Am, americium; U, uranium]

\begin{tabular}{lccc}
\hline \multirow{2}{*}{ Sample } & \multicolumn{3}{c}{ Ratio of AEX to (FAB and XAD-AEX) } \\
\cline { 2 - 4 } & Pu 239 and 240 & Am 241 & U 233 and 234 \\
\hline Well 1587 & 0.91 & 1.07 & 0.99 \\
SW-51 & 0.95 & 1.07 & 1.05 \\
SW-53 & 0.98 & 0.97 & 1.05 \\
\hline
\end{tabular}

\section{Organic Chemistry}

The results of the dissolved organic carbon (DOC) analysis and isolation of fulvic acid are listed in table 24. The ground-water sample had a low DOC concentration and fulvic-acid concentration, which is typical for ground water (Thurman, 1985). The two surface-water samples had higher DOC concentrations than the ground water. In SW-51, about one-half of the DOC was fulvic acid, which is typical for surface water. In contrast, SW-53 had a higher DOC concentration than SW-51, but a lower fulvic-acid concentration. The lower percent of the DOC that was fulvic acid at SW-53 may indicate the sorption of fulvic acid on the abundant iron-oxide rich particles.

The carbon distribution in the isolated fulvic acid was characterized using solid state ${ }^{13} \mathrm{C}-\mathrm{NMR}$ spectroscopy (fig. 6). The fulvic acids isolated from all three sites had characteristics similar to other soil-derived dissolved fulvic acids from oxidizing systems, including pronounced carboxylic-acid peaks (sharp peak around $175 \mathrm{ppm}$ ). The concentration of carboxylic-acid groups associated with fulvic acids in the water samples was calculated based on the fulvic-acid concentration and relative area of the carboxylic-acid peak in the ${ }^{13} \mathrm{C}-\mathrm{NMR}$ spectrum (table 24 ). For all three samples, the carboxylic-acid concentration exceeded the dissolved $\mathrm{Pu} 239$ and 240 concentration by 9 to 10 orders of magnitude. Such very high ratios of potential complexation sites to $\mathrm{Pu}$ would favor complexes that have large formation constants due to structural or conformational properties of certain fulvic-acid molecules. The concentrations of dissolved $\mathrm{Pu} 239$ and 240 increase with dissolved fulvic acid concentration. The positive relation of fulvic-acid concentration to dissolved Pu activity supports the importance of this chemical interaction. 
A Well 1587 - XAD-8 ELUATE (FULVIC ACID)

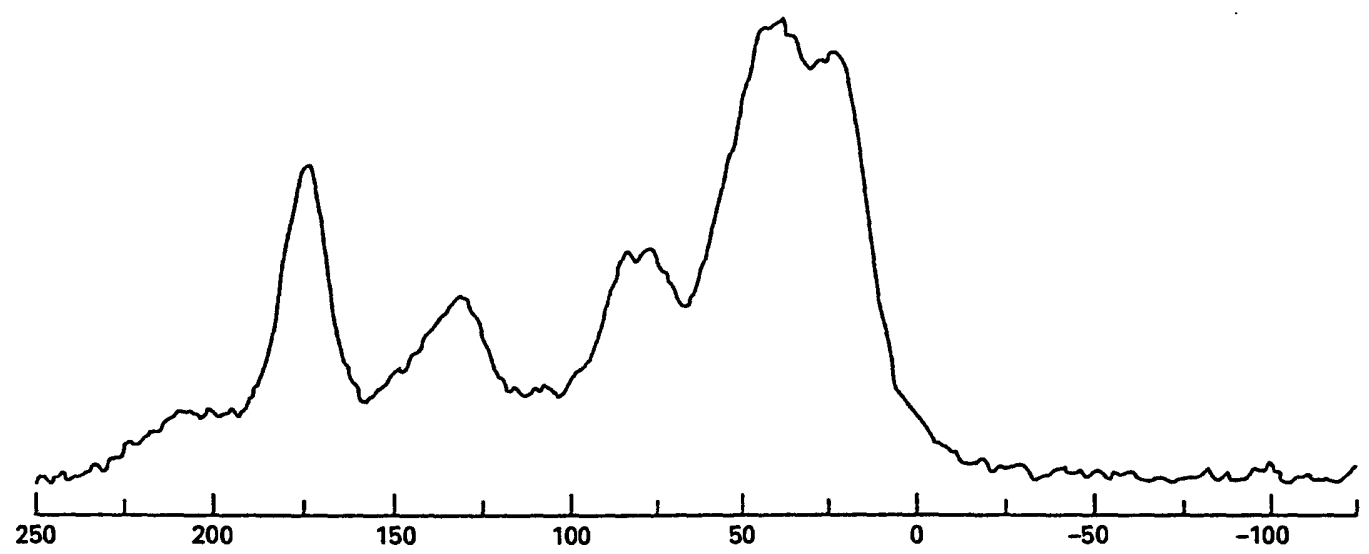

B Well SW-51 - XAD-8 ELUATE (FULVIC ACID)

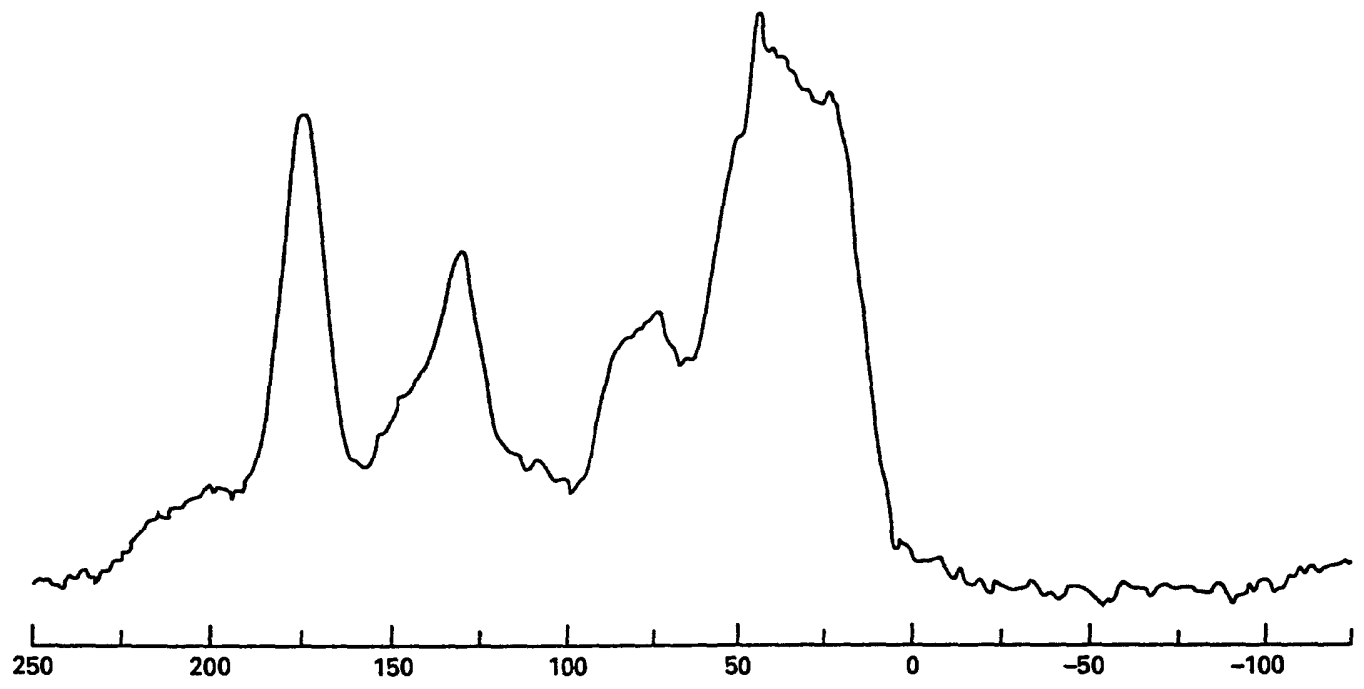

C Well SW-53 - XAD-8 ELUATE (FULVIC ACID)

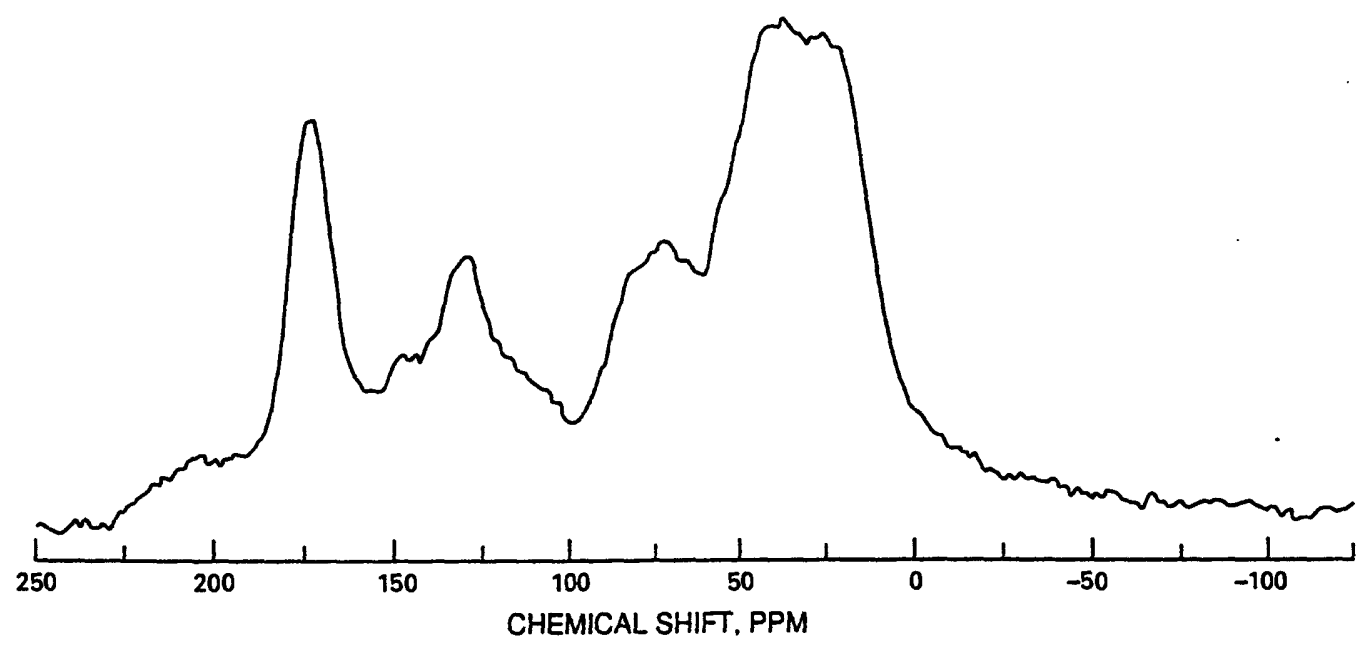

Figure 6. ${ }^{13}$ Carbon-Nuclear Magnetic Resonance spectrum of fulvic acid isolated from the dissolved phase of water from A, well 1587; B, SW-51; and C, SW-53. 
Table 24. Concentration of dissolved organic carbon and fulvic acid in water from Well 1587 and surface-water sites SW-51 and SW-53

[DOC, dissolved organic carbon; $\mathrm{mg} \mathrm{C} / \mathrm{L}$, milligrams carbon per liter, $\mathrm{FAB}-\mathrm{COOH}$, fulvic-acid bound carboxylate concentration; $\mu M$, micromolar, $\mathrm{Pu}$, plutonium; $\mathrm{PCi} / \mathrm{L}$, picocuries per liter, $\mathrm{FAB}$, fulvic-acid bound; $\mathrm{n} M$, nanomolar]

\begin{tabular}{|c|c|c|c|c|c|c|}
\hline Sample & $\begin{array}{c}\text { DOC } \\
\text { (mg C/L) }\end{array}$ & $\begin{array}{l}\text { Fulvic acid } \\
\text { (mg C/L) }\end{array}$ & $\begin{array}{c}\text { FAB-COOH } \\
(\mu \mathrm{M})\end{array}$ & $\begin{array}{c}\text { Totaldissolved } \\
\text { Pu } 230 \text { and } 240 \\
\text { (pCl/L) }\end{array}$ & $\begin{array}{r}\text { FAB } \\
\text { Pu } 239 \text { and } \\
\text { (PCi/L) }\end{array}$ & $\begin{array}{l}\text { B } \\
\text { d } 240^{1,2} \\
(n M)\end{array}$ \\
\hline Well 1587 & 1.3 & 0.23 & 2.8 & $1.2 \times 10^{-2}$ & $7.4 \times 10^{-3}$ & $0.55 \times 10^{-6}$ \\
\hline SW-51 & 2.3 & 1.04 & 15 & $5.9 \times 10^{-2}$ & $5.2 \times 10^{-2}$ & $3.9 \times 10^{-6}$ \\
\hline SW-53 & 4.0 & 0.90 & 12 & $3.1 \times 10^{-2}$ & $2.3 \times 10^{-2}$ & $1.7 \times 10^{-6}$ \\
\hline
\end{tabular}

Other major peaks in the ${ }^{13} \mathrm{C}$-NMR spectra are aliphatic or $\mathrm{sp}^{3}$ hybridized carbons $(0-50 \mathrm{ppm})$, oxygenbonded aliphatic carbons (peak centered at $76 \mathrm{ppm}$ ), and aromatic or $\mathrm{sp}^{2}$ hybridized carbons (110-160 ppm). The aliphatic peak in these spectra is a partial doublet; the leading part representing methyl carbons and the trailing part representing interior methylene carbons. The pronounced methyl peak indicates that the aliphatic moieties in the fulvic acids are highly branched in structure. The oxygen-bonded carbon peak generally represents residual carbohydrate carbons originating from the degradation of cellulose of vascular plants. The presence of aromatic carbons with only a small phenolic shoulder and little or no indication of methoxyl carbon indicates that the aromatic structures are derived from highly altered (oxidized) lignin. Fulvic acids that have similar ${ }^{13} \mathrm{C}-\mathrm{NMR}$ spectra are present in many freshwaters; these fulvic-acid samples, and presumably any capacity to complex $\mathrm{Pu}$, are not unusual or unique.

\section{Electrophoretic Mobility}

Electrophoretic mobility is a measure of the charge density of an aqueous particle and is measured by applying an external electrical field across a solution containing charged particles. The sign and magnitude of the charge are obtained by measuring the velocity and direction of the particle under this field. Units are in velocity per unit electric field: velocity/field $=$ (micrometers per second)/(volt per centimeter). The greater the charge density on the particle, the higher the electrophoretic mobility value (Ranville and others, 1991). In most natural water, the electrophoretic mobility of suspended particles is negative and remarkably uniform (Ranville and others, 1991). With few exceptions, natural particles have electrophoretic mobility values of about -0.5 to $-2.5(\mu \mathrm{m} / \mathrm{s}) /$ $(\mathrm{V} / \mathrm{cm})$. Because most ground-water matrices and sediment surfaces carry a negative charge, negatively charged particles are expected to be more mobile than positively charged particles (McCarthy and Zachara, 1989).

Results of electrophoretic mobility measurements on samples of the particulate retentate and on the colloidal retentates are listed in table 25 . All fractions are negatively charged and are in the normal range of electrophoretic mobility values for natural water. The values are near the low end of this range, consistent with values expected for hard water and with minerals that are coated with organic material. The values may not be high enough to provide extensive electrostatic stabilization, although the negative charge on these particles is unfavorable for deposition of these particles on the soil matrix. There is a small increase in negative electrophoretic mobility values for the 10,000-Dalton retentate in samples at all three sites, indicating that the smallest colloids are potentially more mobile and less likely to interact electrostatically with soil and sediment surfaces. 
Table 25. Electrophoretic mobility of particles recovered by filtration of water from Well 1587 and surface-water sites SW-51 and SW-53

$[\mu \mathrm{m} / \mathrm{s} / \mathrm{V} / \mathrm{cm}$, micrometers per second divided by volts per centimeter, $>$, greater than; $\mu \mathrm{m}$, micrometer,,-- no data]

\begin{tabular}{llccc}
\hline \multicolumn{5}{c}{$\begin{array}{c}\text { Electrophoretic mobility } \\
(\mu \mathrm{m} / \mathrm{s} / \mathrm{N} / \mathrm{cm})\end{array}$} \\
\hline \multicolumn{1}{c}{ Phase } & \multicolumn{1}{c}{ Size } & Well 1587 & sW-51 & sW-53 \\
\hline Particulate & $>5 \mu \mathrm{m}$ & $-1.04 \pm 0.06$ & $-1.05 \pm 0.04$ & - \\
Colloid & $0.45 \mu \mathrm{m}-5 \mu \mathrm{m}$ & $-1.01 \pm 0.08$ & $-1.03 \pm 0.05$ & $1-0.77 \pm 0.05$ \\
Colloid & 100,000 Daltons - 0.45 $\mu \mathrm{m}$ & - & $-0.97 \pm 0.06$ & $-0.85 \pm 0.05$ \\
Colloid & 10,000 Daltons - 100,000 Daltons & $-1.24 \pm 0.03$ & $-1.15 \pm 0.05$ & $-1.07 \pm 0.04$ \\
\hline
\end{tabular}

${ }^{1} 0.45 \mu \mathrm{m}-3 \mu \mathrm{m}$ for site SW-53

\section{CONCLUSIONS}

1. Substantial percentages of total Pu 239 and 240 and Am 241 activity are associated with particulate phases in ground water and particulate and colloidal phases in surface water, despite the large variation in the total concentration of the particulate and colloidal phases.

2. Uranium 233 and 234 are predominantly in the dissolved phase, again independent of particulate and colloidal concentrations.

3. A substantial percentage of dissolved $\mathrm{Pu} 239$ and 240 is complexed by dissolved fulvic acid, and the concentrations of dissolved $\mathrm{Pu} 239$ and 240 increases with dissolved fulvic-acid concentration.

4. Dissolved cationic forms account for very low percentages of dissolved Pu 239 and 240, Am 241, and $\mathrm{U} 233$ and 234.

5. Dissolved U 233 and 234 and Am 241 are predominantly anionic in nature, but not associated with dissolved fulvic acids, indicating the possible importance of other organic ligands or inorganic anionic species.

\section{REFERENCES}

Aiken, G.R., 1985, Isolation and concentration techniques for aquatic humic substances, in Aiken, G.R., MacCarthy, P., McKnight, D.M., Wershaw, R.L., eds., Humic Substances in Soil, Sediment, and Water: New York, John Wiley, p. 363386.

Aiken, G.R., McKnight, F.M., Thom, K.A., and Thurman, E.M., 1992, Isolation of hydrophilic acids from water using nonionic macroporous resins: Organic Geochemistry, v. 18, no. 4, p. 567-573.

Ball, J.W., and Nordstrom, D.K., 1991, Users manual for WATEQ4F, with revised thermodynamic data base and test cases for calculating speciation of major, trace, and redox elements in natural waters: U.S. Geological Survey Open-File Report 91-193, 189 p.

Barthel, K.G., Schneider, G., Gradinger, R., and Lenz, J., 1989, Concentration of live pico- and nanoplankton by means of tangential flow filtration: Journal of Plankton Research, v. 11, p. 1213-1221.

Buddemeier, R.W., and Hunt, J.R., 1988, Transport of colloidal contaminants in groundwater radionuclide migration at the Nevada Test Site: Applied Geochemistry, v. 3, p. 535-548. 
Buffle, J., De Vitre, R.R., Perret, D.F., and Leppard, G.G., 1989, Physico-chemical characteristics of a colloidal iron phosphate species formed at the oxic-anoxic interface of a eutrophic lake: Geochimica et Cosmochimica Acta, v. 53, p. 399-408.

Buffle, J., Perret, D.F., and Newman, M., 1992, The use of filtration and ultrafiltration for size fraction of aquatic particles, colloids, and macromolecules, in Buffle, J., and vanLeenwen, H.P., eds., Environmental particles: Chelsea, Mich., Lewis Publishers, p. 171-230.

Coughtrey, P.J., Jackson, D., Jones, C.H., Kane, P., and Thorne, M.C., 1984, Radionuclide distribution and transport in terrestrial and aquatic ecosystems; a critical review of data: Boston, A.A. Balkema, 548 p.

Dahlman, R.C., Bondietti, E.A., and Eyman, L.D., 1976, Biological pathways and chemical behavior of plutonium and other actinides in the environment, in Friedman, A.M., ed., Actinides in the environment: ACS [American Chemical Society] Symposium Series 35, p. 47-80.

Degueldre, C., Baeyens, B., Gorelich, W., Riga, J., Verbist, J., and Stadlemann, P., 1989, Colloids in water from a subsurface fracture in granitic rock, Grimsel Test Site, Switzerland: Geochimica et Cosmochimica Acta, v. 53, p. 603-610.

EG\&G 1991, Rocky Flats Plant site environmental report for 1990: RFP-ENV-90, 210 p.

Gutman, R.G., 1987, Membrane filtration-The technology of pressure driven crossflow processes: Bristol, England, Adam Hilger, $210 \mathrm{p}$.

Harnish, R.A., McKnight, D.M., and Ranville, J.F., 1994, Particulate, colloidal, and dissolved-phase association of plutonium and americium in a water sample from Well 1587 at the Rocky Flats Plant, Colorado: U.S. Geological Survey Water-Resources Investigations Report 93-4175, $27 \mathrm{p}$.

Harvey, R.W., George, L.H., Smith, R.L., and LeBlanc, D.R., 1989, Transport of microspheres and indigenous bacteria through a sandy aquifer-Results of natural and forced-gradient tracer experiments: Environmental Science and Technology, v. 23, p. 51-56.

Hernandez, L.K., and Stallard, R.F., 1988, Sediment sampling through ultrafiltration: Journal of Sedimentary Petrology, v. 58, p. 758-759.

Leenheer, J.A., Meade, R.H., Taylor, H.E., and Periera, W.E., 1989, Sampling, fractionation, and dewatering of suspended sediment from the Mississippi River for geochemical and trace-contaminant analysis, in Mallard, G.E., ed., U.S. Geological Survey Toxic Substances Hydrology Program-Proceedings of the technical meeting, Phoenix, Ariz., September 26-30, 1988: U.S. Geological Survey Water-Resources Investigations Report 88-4220, p. 501-511.

McCarthy, J.F., and Zachara, J.M., 1989, Subsurface transport of contaminants: Environmental Science and Technology, v. 23, p. 496-502.

McKnight, D.M., Behmel, P., Francko, D.A., Gjessing, E.T., Münster, U., Petersen, R.C., Jr., Skulberg, O.M., Steinberg, C.E.W., Tipping, E., Visser, S.A., Werner, P.W., and Wetzel, R.G., 1990, Group report-How do organic acids interact with solutes, surfaces, and organisms?, in Perdue, E.M., and Gjessing, E.T.,eds., Organic acids in aquatic ecosystems: New York, John Wiley, p. 223-243.

McKnight, D.M., Kimball, V.A., and Bencala, KE., 1988, Iron photoreduction and oxidation in an acidic mountain stream: Science, v. 240, p. 637-640.

McKnight, D.M., Bencala, K.E., Zellweger, G.W., Aiken, G.R., Feder, G.L., and Thorn, K.A., 1992, Sorption of dissolved organic carbon by hydrous aluminum and iron oxides occurring at the confluence of Deer Creek with the Snake River, Summit County, Colorado: Environmental Science and Technology, v. 26, no. 7, p. 1388-1396.

McKnight, D.M., and Wershaw, R.L., 1989, Complexation of copper by fulvic acid from the Suwannee River-Effect of counter-ion concentration, in Averett, R.C., and others, Humic substances in the Suwannee River, Georgia-Interactions, properties, and proposed structures: U.S. Geological Survey Open-File Report 87-557, p. 59-80.

Onishi, Y., Serne, R.J., Arnold, C.E., and Thompson, F.L., 1981, Critical review-Radionuclide transport, sediment transport, water quality mathematical modelling, and radionuclide adsorption/desorption mechanisms: NUREG/CR-1322, PLN/ U.S. Nuclear Regulatory Commission, 339 p.

Penrose, W. R., Polzer, W.L., Essington, E.H., Nelson, D.M., and Orlandini, K.A., 1990, Mobility of plutonium and americium through a shallow aquifer in a semiarid region: Environmental Science and Technology, v. 24, p. 228-234.

Ranville, J.F., 1992, Factors influencing the electrophoretic mobility of suspended sediments in acid mine drainage: Golden, Colorado School of Mines, Ph.D. dissertation, 270 p.

Ranville, J.F., Harnish, R.A., and McKnight, D.M., 1991, Particulate and colloidal organic material in Pueblo Reservoir, Colorado-Influence of autochthonous source on chemical composition, in Baker, R.A., ed., Organic substances and sediments in water: Chelsea, Mich., Lewis Publishers, p. 47-73.

Ryan, J.N., 1988, Groundwater colloids in two Allantic Coastal Plain aquifers-Colloid formation and stability; Cambridge, Massachusetts Institute of Technology, M.S. thesis, $250 \mathrm{p}$. 
Rockwell Intemational 1987, Draft remedial investigation report for 903 pad, mound, and east trenches areas: Golden, Colo., U.S. Department of Energy, Rocky Flats Plant, 212 p.

Salbu, B., Bjornstad, HE., Lindstrom, N.S., Lydersen, E., Brevik, E.M., Rambaek, J.P., and Paus, P.E., 1985, Size fractionation techniques in the determination of elements associated with particulate or colloidal material in natural fresh water: Talanta, v. 32, p. 907-913.

Thurman, E.M., 1985, Aquatic humic substances, in Thurman, E.M., ed., Organic geochemistry of natural waters: Boston, Martinus/Nijhoff, p. 273-287.

Thurman, E.M., and Malcolm, R.L., 1981, Preparative isolation of aquatic humic substances, Environomental Science and Technology 15: p. 463-466.

Whitehouse, B.G., Patrick, G., and Ehrhardt, M., 1986, Crossflow filtration of colloids from Baltic Sea water: Water Research, v. 20, p. 1599-1601. 